
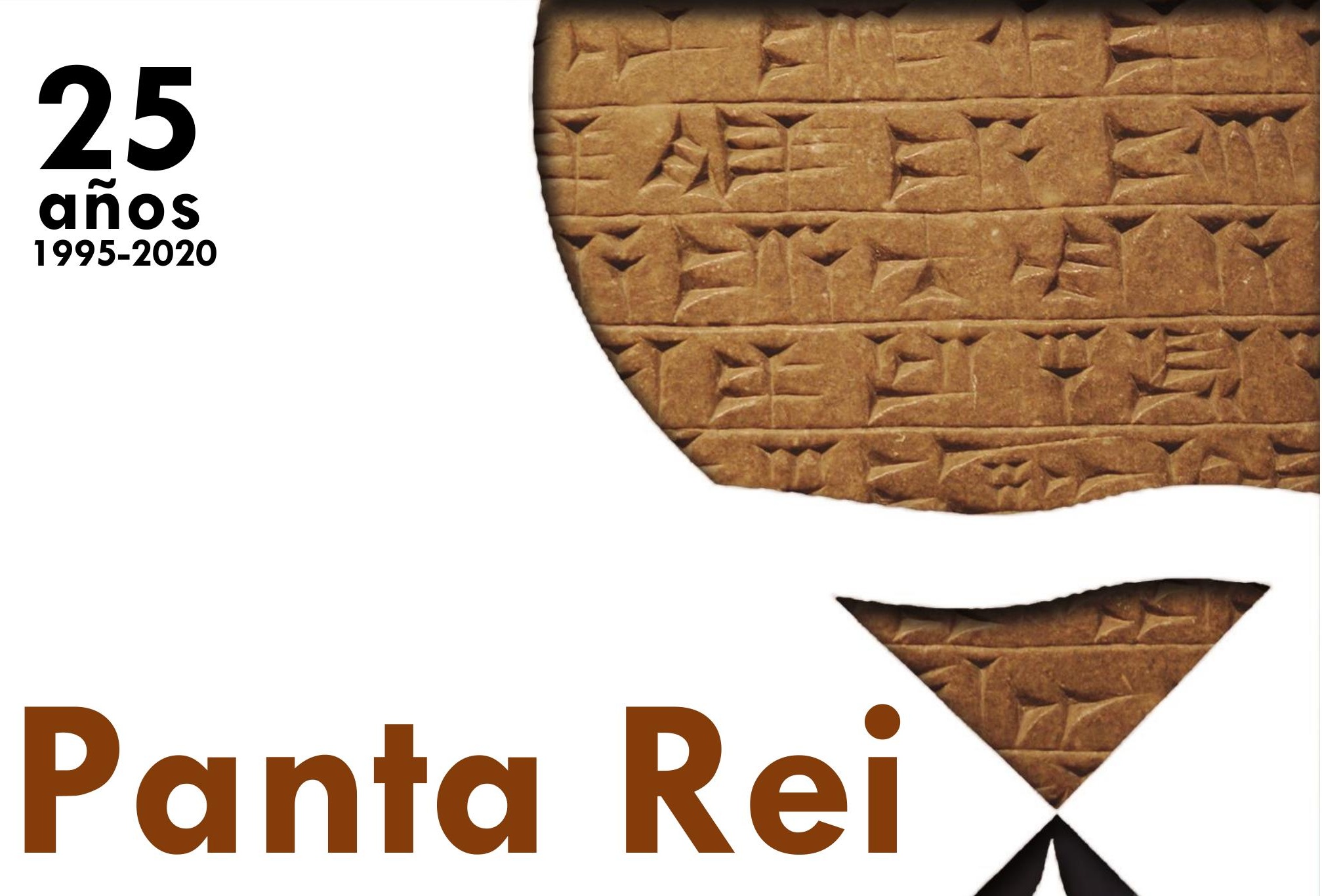

Revista digital de Historia y didáctica de la Historia 


\section{0 (2)}

Revista anual

Fecha de inicio: 1995

Revista Panta Rei. pantarei@um.es

\section{Edita:}

Centro de Estudios del Próximo Oriente y la Antigüedad Tardía - CEPOAT

Edificio Universitario Saavedra Fajardo.

Universidad de Murcia

C/ Actor Isidoro Máiquez, 9

30007 - MURCIA - ESPAÑA

Teléfono: $(+34) 868883890$

cepoat@um.es

Web: www.um.es/cepoat/pantarei

Ediciones de la Universidad de Murcia - EDITUM

Edificio Pleiades. Campus de Espinardo.

Universidad de Murcia

C/ Campus, s/n

30100 - MURCIA - ESPAÑA

Teléfono: $(+34) 868883013$

editum@um.es

Web: https://www.um.es/web/editum/

En portada: Montaje elaborado a partir de fotografía de una inscripción sumeria del British Museum (Wikimedia) (arriba) y fotografía de Miguel Martínez Sánchez (abajo)

Edición 2020 (2)

ISSNe: 2386-8864

ISSN: $1136-2464$
Responsables de los textos: sus autores.

Responsable de la presente edición: Consejo Editorial de Panta Rei.

Depósito legal: MU-966-1995 


\section{CONSEJO DE REDACCIÓN}

Coordinador editorial

Egea Vivancos, Alejandro [Didáctica de las Ciencias Sociales, Universidad de Murcia]

Secretaria

Arias Ferrer, Laura [Didáctica de las Ciencias

Sociales, Universidad de Murcia]

Editores

Jiménez Vialás, Helena [Historia Antigua, Universidad de Murcia]

Martínez Gil, Tània [Didáctica de las Ciencias

Sociales, Universidad de Barcelona]

Meseguer Gil, Antonio José [Historiador, Profesor de

Secundaria]

Ortiz García, Jónatan [Arqueología, Universidad de

Alcalá de Henares]

Romero Molero, Alberto [Arqueología, Universidad

Isabel I]

Sáez Giménez, David Omar [Historiador, Profesor

de Secundaria]

Sáez Rosenkranz, Isidora V. [Didáctica de las

Ciencias Sociales, Universidad de Barcelona]

Sánchez Mondejar, Celso Miguel [Arqueólogo,

Patrimonio Inteligente]

Responsable informático

Martínez García, José Javier [CEPOAT, Universidad de Murcia]

Responsables de traducción y corrección lingüística Martínez Martínez, Cristina [Profesora de Secundaria, Sociedad Española de Lenguas Modernas] Albaladejo Albaladejo, Sara [ISEN-Universidad de Murcia]

\section{CONSEJO ASESOR}

Adroher Auroux, Andrés María [Arqueología, Universidad de Granada]

Albero Muñoz, $M^{a}$ del Mar [H. ${ }^{a}$ del Arte, Universidad de Murcia]

Alia Miranda, Francisco [Historia Contemporánea, UCLM]

Arciniega García, Luis [Historia del Arte, Universidad de Valencia]

Barrio Barrio, Juan Antonio [Historia Medieval,

Universidad de Alicante]

Castellano i Solé, Núria [Egiptología, Schola

Didàctica Activa S.L.]

Chapman, Arthur [History Education, University

College of London, Reino Unido]

Cid López, Rosa María [Historia Antigua, Universidad de Oviedo]

Cobacho López, Ángel [Derecho, Universidad de Murcia]

Cuenca López, José María [Didáctica de las Ciencias Sociales, Universidad de Huelva]
Egea Bruno, Pedro M. ${ }^{a}$ [Historia Contemporánea, Universidad de Murcia]

Feijoo Martínez, Santiago [Arqueología, Consorcio

Ciudad Monumental de Mérida]

García Atienzar, Gabriel [Prehistoria, Universidad de

Alicante]

Ginestí Rosell, Anna [Filología Clásica, Katholische

Universität Eichstätt-Ingolstadt]

González Monfort, Neus [Didáctica de las

Ciencias Sociales, Universidad Autónoma de

Barcelona]

González Soutelo, Silvia [Arqueología, Universidad de Vigo]

Haber Uriarte, María [Prehistoria, Universidad de Murcia]

Hernández de la Fuente, David [Filología Clásica, Universidad Complutense]

Hutson, Scott R. [Anthropology, University of Kentucky, EEUU]

Igual Luis, David [Historia Medieval, UCLM]

Irigoyen López, Antonio [Historia Moderna,

Universidad de Murcia]

Jover Maestre, Francisco Javier [Prehistoria,

Universidad de Alicante]

Mahony, Simon [Digital Humanities, University College of London, Reino Unido]

Marsilla de Pascual, Francisco Reyes [Técnicas

historiográficas, Universidad de Murcia]

Martínez-Burgos García, Palma [H. ${ }^{a}$ del Arte, UCLM]

Mathis, Christian [Didaktik der Geschichte, PH Zürich]

Miralles Maldonado, José Carlos [Filología Clásica,

Universidad de Murcia]

Molina Gómez, José Antonio [Historia Antigua,

Universidad de Murcia]

Mónica Ghirardi [Historia Moderna, Universidad

Nacional de Córdoba, Argentina]

Navarro Espinach, Germán [Historia Medieval,

Universidad de Zaragoza]

Noguera Celdrán, José Miguel [Arqueología,

Universidad de Murcia]

Ortiz Heras, Manuel [Historia Contemporánea, UCLM]

Panzram, Sabine [Historia Antigua, Universität

Hamburg]

Pérez Molina, Miguel Emilio [Filología Clásica,

Universidad de Murcia]

Prados Martínez, Fernando [Arqueología,

Universidad de Alicante]

Sánchez lbáñez, Raquel [Didáctica de las Ciencias

Sociales, Universidad de Murcia]

Sancho Gómez, Miguel Pablo [Educación, UCAM]

Victoria Moreno, Diego [Historia Contemporánea,

UNED]

Vilar García, María José [Historia Contemporánea,

Universidad de Murcia]

Vivas Sainz, Inmaculada [H. ${ }^{a}$ del Arte, UNED]

Zamora López, José Ángel [Próximo Oriente Antiguo,

CCHS-CSIC] 



\section{Índice}

1995-2020. 25 años de Panta Rei

Equipo editorial

La Historia social aplicada a la antigua Mesopotamia: cambios historiográficos y nuevas vías de 9 investigación

Josué Javier Justel Vicente

A Look Back into Ancient Egyptian Linguistic Studies (c. 1995-2019)

Carlos Gracia Zamacona

La infancia en la antigua Mesopotamia: 25 años de investigación

Daniel Justel Vicente

Conflictos armados y su tratamiento en educación. Análisis de la producción científica de los últimos

25 años en la Web of Science

Naiara Vicent, Janire Castrillo, Alex Ibañez-Etxeberria y Leire Albas

La investigación en pensamiento histórico. Un estudio a través de las tesis doctorales de Ciencias

Sociales (1995-2020)

Álvaro Chaparro Sainz, M.a del Mar Felices de la Fuente y Laura Triviño Cabrera

Las narrativas nacionales en la enseñanza y el aprendizaje de la historia: Una revisión sobre los libros de texto y las narrativas de los estudiantes

César López Rodríguez

La historia de las personas: reflexiones desde la historiografía y de la didáctica de las ciencias sociales durante los últimos 25 años

Mariona Massip Sabater, Jordi Castellví Mata y Joan Pagès Blanch †

Panorámica de la trilogía cine, historia y educación en España (1995-2020) 



\title{
La historia de las personas: reflexiones desde la historiografía y de la didáctica de las ciencias sociales durante los últimos 25 años
}

\section{People's History: Reflections from Historiography and Social Sciences Didactics from the Last 25 Years}

\author{
Mariona Massip Sabater \\ Universitat Autònoma de Barcelona \\ mariona.massip@uab.cat \\ 0000-0002-7054-8819
}

\author{
Jordi Castellví Mata \\ Universitat Autònoma de Barcelona \\ jordi.castellvi.mata@uab.cat \\ 0000-0002-6487-5477
}

\author{
Joan Pagès Blanch $\dagger$ \\ Universitat Autònoma de Barcelona \\ joan.pages@uab.cat \\ 0000-0001-8650-3976
}

Recibido: $31 / 01 / 2020$

Aceptado: 08/05/2020

\section{Resumen}

En este artículo se revisa la evolución de la ciencia histórica y de la historia escolar a lo largo de los últimos 25 años. Esta revisión se centra en los avances en la investigación y la enseñanza de la historia de las personas; es decir, aquella que atiende a la totalidad de agentes sociales e históricos, que se articula a partir de la proyección global de la humanidad y que atiende a los problemas de las experiencias humanas. En primer lugar, se concreta el concepto de historia escolar y se explica la relación que se establece entre la historia escolar y la historiografía. En segundo lugar, se analiza la evolución de ambas a lo largo de estos 25 años. Finalmente, se plantean retos de futuro. Existe un desequilibrio entre la evolución del conocimiento histórico y el impacto que ha tenido en el currículo escolar. La historia escolar sigue centrada, de manera mayoritaria, en los procesos políticos nacionales, y reproduciendo saberes androcéntricos y eurocéntricos en los que se excluyen la gran mayoría de protagonistas.

\section{Palabras clave}

Historiografía, Enseñanza de la Historia, Ciencias Sociales, Civismo.

\begin{abstract}
In this article the evolution of historical science and school history over the past 25 years is reviewed. This review focuses on advances in people's history; that is, a history in which all social and historical agents are recognised, and which is articulated from the global consideration of humanity and human experiences. In the first place, the meaning of school history is specified, along with the relationship between school history and historiography. Secondly, the evolution of both over these 25 years is analysed. Finally, we pose future challenges.

There is an imbalance between the evolution of historical knowledge and the impact it has had on the school curriculum and educational practices. School history continues to reproduce androcentric and Eurocentric knowledge based on political processes in which the great majority of protagonists are excluded.
\end{abstract}

\section{Keywords}

Historiography, History Instruction, Social Sciences, Civics.

Para citar este artículo: Massip Sabater, M., Castellví Mata, J. y Pagès Blanch, J. (2020). La historia de las personas: reflexiones desde la historiografía y de la didáctica de las ciencias sociales durante los últimos 25 años. Panta Rei: revista digital de Historia y didáctica de la Historia, 167-196. doi: $10.6018 /$ pantarei.445831 


\section{Introducción}

Maria-Nova, protagonista de Becos de memória, buscaba sentido a su clase de historia: aquello que le leía la profesora le parecía distante porque difería de aquello que ella tenía "escrito, cravado e gravado no seu corpo, na sua alma, na sua mente" (de Oliveira, 2018 , p. 104). No se encontraba en temas que nada tenían que ver con la vida, con su vida, ni en unos protagonistas mitificados y procedentes de élites políticas y económicas que no representaban la sociedad en la que vivía, con los que no se identificaba.

Para Fontana, el mayor de los desafíos que se ha planteado la historia es "el de superar el viejo esquema tradicional que explicaba una fábula de progreso universal en términos eurocéntricos y que tenía como protagonistas esenciales a los grupos dominantes, políticos y económicos, de las sociedades desarrolladas" (2013, p. 166). Y no lo entendía como un reto sólo historiográfico, sino también educativo. Fontana ha sido uno de los pocos historiadores que se ha preocupado por la enseñanza de la historia (Pagès, 2019), consciente del papel que se ha otorgado tradicionalmente a la historia escolar: la difusión de una visión concreta de la historia nacional al conjunto de la población (Fontana, 2013).

La articulación de unos contenidos sociales escolares -especialmente históricos- al servicio de los intereses de los estados-nación y de sus clases dirigentes, ha sido extensamente estudiada y señalada. El reto de una historia de todas las personas que permita construir una imagen no excluyente de la sociedad, que nos permita entendernos como personas, como humanos, se nos hace urgente. Por esta razón se plantea este trabajo como un reto para la didáctica y la enseñanza de los contenidos históricos escolares.

En un primer apartado explicamos a qué nos referimos cuando hablamos de historia escolar, y los diferentes elementos que participan en ella (apartado 3.1.). También incidimos en las relaciones y diferencias entre los conocimientos históricos académicos y escolares, entre la investigación historiográfica y la didáctica (apartado 3.2.). Seguidamente analizamos la evolución de ambas a lo largo de estos 25 años desde la perspectiva de la historia de las personas (apartados 4 y 5). Lo hacemos de manera asimétrica, deteniéndonos especialmente en la evolución historiográfica para subrayar los avances de la historia académica que podrían ser aprovechados, desde la historia escolar, para afrontar el reto de superar los contenidos históricos socialmente excluyentes. Finalmente, planteamos algunos retos de futuro (apartado 6).

\section{Méłodo}

Para abordar la evolución historiográfica hemos consultado trabajos de revisión historiográfica contemporánea publicados en diferentes momentos de los últimos 25 años. Hemos escogido aquellos que refieren a la historiografía occidental sin limitarse en escuelas nacionales, y publicados en lengua castellana. Han sido especialmente importantes las obras de Burke (1996) e lggers (1998) para ilustrar el inicio del periodo estudiado; Hernández (2004) y Fontana (2000/2013ㄹ) en relación a mitad del periodo, y de Aurell,

1 El trabajo original es del año 2000. La versión utilizada para el artículo es producto de una revisión y reedición de 2013. 
Balmaceda, Burke y Soza (2013) y Guldi y Armitage (2016) en el caso de la última década. A partir del análisis de las temáticas podemos entender no sólo la caracterización y clasificación de esta evolución por parte de los diferentes autores, sino también cómo han cambiado algunas preocupaciones a lo largo de estos años. Analizamos las tendencias desde la perspectiva de la proyección de la historia de -todas- las personas, y usamos artículos y trabajos históricos e historiográficos específicos para complementar y concretar algunas líneas e ideas. Haremos referencia al desarrollo de la historiografía occidental. Para facilitar la redacción y lectura del artículo, usaremos formas verbales impersonales, aunque entendemos que no hay historiografía sin las personas que generan el trabajo historiográfico.

Para la evolución del currículum escolar hemos usado el análisis temático. La vinculación entre la historia académica y la escolar se ha establecido a partir de publicaciones que abordan esta relación de manera específica. Nos ubicamos en aquellos planteamientos que entienden que la investigación histórica y la investigación didáctica son ciencias distintas que responden a necesidades y objetivos diferentes.

\section{Entre la Historia Académica y la Historia Escolar}

\section{1. ¿De qué hablamos cuando hablamos de hisłoria escolar?}

Antes de abordar la evolución de la investigación histórica y de la historia escolar durante estos 25 años, es interesante ubicar y diferenciar estos conceptos. Por historia escolar entendemos los contenidos históricos que se aprenden y se enseñan en contextos de educación reglada. La selección y organización de los saberes y conocimientos a enseñar, las metodologías, la evaluación y las actividades de aprendizaje configuran el currículum. El currículum tiene diferentes niveles de concreción: el currículum oficial es aquel diseñado desde las instituciones públicas, y que está sujeto a presiones políticas e ideológicas de diferentes agentes (Ballbé, 2019). Desde las teorías críticas de la educación se cuestiona el currículum como un órgano ideológico que perpetúa los intereses y visiones de una cultura hegemónica (Apple, 1998; Giroux, 1990). Es importante diferenciar las prescripciones del currículum oficial de aquello que, en cada aula, se enseña y se aprende, ya que en último término es el profesorado quien toma decisiones sobre el currículum y lo concreta en cada aula. Lo hace en función de sus marcos de referencia (Thornton, 1994, en Ballbé, 2019), de su contexto y circunstancias, de sus alumnos, de los objetivos, y finalidades que otorgue, en este caso, a la enseñanza de las ciencias sociales.

Por otro lado, la didáctica de las ciencias sociales (DCS) es la ciencia que estudia los problemas educativos que surgen de la enseñanza y el aprendizaje de las Ciencias Sociales (Pagès y Santisteban, 1994), en las que se incluyen los contenidos de la historia escolar. Se orienta a la formación del profesorado de Ciencias Sociales (CCSS) y ha de disponer de conocimientos teóricos y prácticos para intentar dar respuesta a las finalidades de la enseñanza de las CCSS - ipara qué enseñar? -, a los contenidos - iqué enseñar? -, y a las metodologías - ¿̇cómo hacerlo mejor? - (Benejam y Pagès, 2004). 


\subsection{La relación entre la historia académica y la historia escolar}

La investigación en didáctica -tanto si se aborda de manera global desde la DCS como si se focaliza en la didáctica de la historia- tiene objetivos y metodologías distintos a las de la historiografía, en tanto que la historia escolar y la historia científica tienen propósitos y objetivos diferentes. Los conocimientos que se seleccionan desde las aulas para dar respuesta a las necesidades educativas proceden de las disciplinas científicas y tendrían que estar actualizados. El proceso de transformación del saber sabio o científico a los saberes escolares (Benejam, 2004) lo conocemos como transposición didáctica (Chevallard, 1991). Según Lautier (2006), la transposición consiste en modificar y contextualizar los saberes históricos en función de la etapa educativa, el contexto educativo y los diferentes actores sociales que ejercen presión para dar forma al saber escolar.

Rina y de la Montaña (2019) entienden que las personas configuramos los imaginarios del pasado a través de diferentes vías. Entre ellas figuran el pasado académico, que identificamos con la historiografía, y el pasado estudiado, conformado por la historia escolar. Para estos autores, la historia escolar "selecciona e integra en el canon nacional determinados acontecimientos y personajes" y "puede ser independiente de la producción historiográfica académica" (p. 291). El valor social del conocimiento histórico se refleja en la enseñanza de la historia, sin embargo, el conocimiento histórico y el conocimiento histórico escolar no son lo mismo, de la misma forma que no son lo mismo la historia y la didáctica de la historia (Pagès, 2018). Este autor expone cuatro elementos de divergencia entre los dos conocimientos: 1) los destinatarios, 2) los propósitos y las finalidades, 3) la selección de contenidos, y 4) la complejidad textual.

En primer lugar, los destinatarios del conocimiento histórico son los historiadores e historiadoras, los estudiantes de historia y, en menor medida, el público en general, mientras que la historia escolar está destinada a estudiantes de niveles educativos no universitarios. En segundo lugar, la investigación histórica pretende arrojar luz sobre los hechos históricos del pasado para comprender nuestro presente, en cambio, la historia escolar suele tener una función socializadora. La selección de contenidos también es distinta. Mientras que desde la historia se ha abierto la puerta a la diversificación de los protagonistas y de las perspectivas, la historia escolar sigue siendo mayoritariamente cronológica, nacional, factual, eurocéntrica y androcéntrica. Mientras que el saber histórico ha evolucionado y los historiadores e historiadoras han procurado explicar su presente a partir del estudio de la historia, los saberes escolares siguen anclados a ideas muchas veces obsoletas, que no ayudan al alumnado a comprender el mundo complejo en el que viven (Pagès, 2018). Por otro lado, tampoco son lo mismo la historia escolar -los saberes históricos construidos- y los saberes históricos apropiados (Pagès, 2015). Según este autor, los saberes apropiados son "aquellos saberes que construye el alumnado en su aprendizaje y que puede utilizar en la escuela y en su vida cotidiana" (p. 304). En cualquier caso, las relaciones entre la historia que se investiga, la historia escolar y el saber histórico apropiado por el alumnado son complejas.

La investigación histórica ha de ser una fuente de información básica para la selección de contenidos, pero esta no responde a las preguntas que se plantean desde la didáctica acerca de cómo se construye la temporalidad o los conceptos históricos, o cómo se forma el 
pensamiento histórico (Pagès y Santisteban, 2016). Necesitamos la investigación en didáctica para "trazar vías realistas y creíbles que permitan que los conocimientos históricos lleguen a las aulas y generen aprendizaje" (Pagès y Santisteban, 2016, p. 74). El conocimiento histórico se construye a partir de preguntas que nos hacemos desde el presente. Según Santisteban y Pagès (2016), las preguntas que nos hacemos surgen de nuestras inquietudes y preocupaciones sobre las relaciones humanas, nuestras identidades y nuestras raíces, sobre la política, sobre el territorio y su organización, sobre la cultura, sobre el arte... Esta mirada hace del conocimiento histórico un conocimiento provisional y, por lo tanto, no pretende "establecer certezas, sino proporcionar elementos de discusión" (Fontana, 201 1, p. 23). Este es uno de los elementos que hacen del conocimiento histórico un conocimiento complejo, que debe ayudarse de otras ciencias sociales para ser contrastado, y, desde esta interdisciplinariedad, tener la función social de aportar soluciones a los problemas sociales del presente. Sin embargo, habitualmente, el conocimiento histórico ha servido para la creación de identidades nacionales y para aprender a ser 'buenos' ciudadanos y ciudadanas, en vez de fomentar el pensamiento crítico (Pagès, 2002).

Nuestra posición coincide con los autores que defienden una enseñanza de la historia orientada a la formación de la ciudadanía (Barton y Levstik, 2004; Endacott y Brooks, 2018; Santisteban y Pagès, 2016). Endacott y Brooks (2018) defienden "that history educators should foster citizenship" (p. 208). Según Santisteban y Pagès (2016), la historia debe permitir que la ciudadanía comprenda el cambio social en el pasado, para que pueda imaginar un cambio en el futuro, ya que el aprendizaje de los hechos históricos, por sí mismo, no comporta el desarrollo de este tipo de capacidades (Santisteban y Pagès, 2016). Barton y Levstik (2004) consideran que la historia escolar debe ayudar a la ciudadanía a 1 ) pensar quienes somos, 2) aprender a tratar temas y cuestiones significativas y controvertidas, 3) aprender a interpretar los hechos del pasado, 4) saber explicarnos a través de narrativas, y 5) ayudarnos a dibujar futuros posibles. Estos mismos autores entienden que de los y las estudiantes se espera que respondan moralmente cuando aprenden historia.

Pagès (2015) añade a las finalidades propuestas por los anteriores autores, la de la enseñanza de la historia para la formación democrática de la ciudadanía y para poner en valor aquello que tiene en común la historia de la humanidad. Pero, íqué es aquello que tiene en común la historia de la humanidad? ¿Podemos hablar de una historia de la humanidad, de una historia humana, de una historia de -todas- las personas? ¿Qué ha pasado con las preguntas en relación a las personas, nuestros roles, vidas y experiencias, en la historia que se investiga y en la historia que se enseña? En los apartados que siguen, hacemos una pequeña revisión de la evolución historiográfica y de la historia escolar en relación con las preguntas por las personas como objeto del conocimiento histórico y como agentes sociales e históricos. 


\section{Evolución historiográfica}

\subsection{Introducción}

A principios de este año 2020 ha fallecido Delumeau, conocido por sus trabajos sobre el miedo, el paraíso y el infierno. Algo de sus obras debía de haber en la reflexión de Aragón (2000) cuando afirmaba que "la moderna historiografía prueba hasta qué punto puede historiarse todo: el cielo, el infierno, lo crudo, lo cocido, la locura, las representaciones de la felicidad" (p. 17). La historiografía del último cuarto de siglo se ha caracterizado, sobre todo, por esta amplia diversificación de las temáticas y de los objetos de estudio de la investigación histórica, acompañada de una gran diversidad también metodológica y epistemológica. Esta posibilidad de historiarlo todo que refería Aragón en realidad se aleja de la idea de la Historia Total que había proyectado la Nueva Historia; más bien se basa en la idea que "la realidad histórica es inabarcable, como lo es la misma realidad" (Aurell y Burke, 2013b, p. 297). El abandono de la pretensión globalizadora en estudios más microscópicos, locales y temáticos será de una gran importancia a la hora de proyectar una historia más humana que hable de todas las personas, pero será vista en algunos casos como un retroceso en la tarea de la comprensión global de las experiencias y los procesos humanos.

A lo largo de estos 25 años se han iniciado y consolidado nuevas tendencias historiográficas. Estas surgen de la búsqueda de nuevas vías a partir de los años 80'. Los giros antropológicos y lingüísticos, con planteamientos e ideologías posmodernas ayudaron a la pérdida de peso de los referentes teóricos del estructuralismo, el marxismo y los Annales, iniciándose un periodo de crisis (Aurell y Burke, 2013b; Fontana, 2013; lggers, 1998). Para lggers (1998), la posmodernidad "se pasó de la raya en el momento en que (...) negó de forma radical la existencia de toda realidad" (p. 104). A pesar de la heterogeneidad, de la "aparición y consolidación de direcciones historiográficas francamente distintas entre si" (Hernández, 2004, p. 10), la evolución historiográfica de este periodo puede ser caracterizada por:

1) La hegemonía de los planteamientos de la nueva historia cultural. El giro cultural de los años 80'-90' aporta una visión más antropológica de la cultura, más holística y sistémica (Suny, 2002) y en la que toman especial relevancia las dinámicas internas de poder (Butler, 2001; Foucault, 2008). Esto permite revitalizar temas políticos, diplomáticos y religiosos, renovando conceptos como el poder, la violencia, los símbolos, los mitos, los espacios públicos y privados, o los actores sociales.

2) El redescubrimiento de la narración para explicar la experiencia social. La narración, descartada en la reivindicación científica de las décadas anteriores, se entiende ahora como la manera en que los seres humanos entendemos y explicamos el mundo (Baldó, 2009; Fontana 2018; King, 2003, en Den Heyer, 2018). Se enfatiza la función de los sujetos sobre los objetos, priorizando la descripción al análisis y las personas a los contextos (Aurell y Burke, 2013b). Con marcada influencia de Levi-Strauss, la narración se reivindica como un sistema de comunicación científica que convierte la complejidad en más inteligible, convertida en un "paquete transmisible" que toma una forma "intrínsicamente democrática" (Guldi y Armitage, 2016, p. 108). 
3) El interés por temáticas obviadas anteriormente que pretenden conectar la experiencia humana con la historia social. Las emociones, las normas, los valores, las festividades, la cotidianidad, la sexualidad, la crianza, los cuerpos, las relaciones familiares, la alimentación, la lectura, el lenguaje, lo privado. La historia de la vida cotidiana, y privada, toma nuevas dimensiones con la nueva concepción cultural y las influencias de la antropología y la psicología. En este sentido, la diversificación de fuentes a las que recurrir es de capital importancia, en lo que Plummer (1989, en Hernández, 2004, p. 27) considera "expresiones de la vida (...) lanzadas al mundo a millones y que pueden ser de interés para cualquiera que se preocupe en buscarlas".

4) La democratización de la agencia histórica y social que, para Hernández (2004), "se impone hoy con fuerza, de manera masiva" (p. 139). Lejos del historicismo que obviaba la agencia protagónica de personas que no formaran parte de las elites dirigentes $-e$ incluso lejos de los primeros pasos de la historia social que entendía las masas populares desde la homogeneidad-, se reflexiona sobre la voluntad de los grupos y los individuos como agentes causales de los cambios históricos (Aurell y Burke, 2013a). La historia desde abajo había "demostrado que los miembros de las clases inferiores fueron agentes cuyas acciones afectaron al mundo en el que vivieron" (Sharpe, 1996, p. 56). Durante los últimos años esta visión ya se integra en la mayoría de las tendencias historiográficas. Los avances de la microhistoria y de la microsociología (Collins, 1981) refuerzan la tesis que todas las personas generan influencia (Moscovici, 1996). La vida, y las vidas de todas ellas, generan interés histórico.

5) El reconocimiento de la persona historiadora como sujeto que interpreta y crea símbolos y significados. La renuncia a la objetividad positivista y la reivindicación de las propias subjetividades, motivaciones y puntos de vista toman importancia no sólo en la elección de temáticas sino en la manera de abordarlas. El conocimiento histórico queda entonces como una construcción no sólo social y cultural sino también personal. Las críticas feministas y decoloniales a la historiografía se focalizan no sólo en los protagonistas, las temáticas y las ideologías de la historia estudiada, sino en los autores que han sido reconocidos en la historia intelectual (de Oliveira, 2018).

6) La influencia, por un lado, de la antropología, es reconocida como la responsable de los cambios de mayor entidad y transcendencia de la historiografía durante la última década del s. XX (Barnard, 2000). Por otro, las teorías feministas y decoloniales no sólo amplían protagonistas, temáticas y perspectivas, sino que insisten en la deconstrucción epistemológica, en repensar el tiempo histórico (Alderete, 2018) y en desaprender algunos de los conocimientos construidos hasta el momento. Las perspectivas feministas y decoloniales, que se proyectan de la periferia al centro (Aurell y Burke, 2013b), son de especial relevancia en el momento actual: frente a los retos globales de la crisis y el colapso socioambiental del sistema capitalista (Latouche, 2015), toma fuerza la necesidad de reaprender de las experiencias y los espacios oprimidos por el capitalismo, el colonialismo y el patriarcado -articulados en un mismo sistema de opresiones (Santos, 2019)- en la búsqueda de maneras de vivir alternativas.

Aurell y Burke refieren a dos grandes tendencias que se han desarrollado a lo largo de estos últimos 25 años: fragmentación y síntesis, clasificación que aprovechamos a 
continuación. Ambas han estado presentes, pero con tendencia basculante: las de síntesis han ganado peso en los últimos años como reacción a la fragmentación y a las preocupaciones globales de las sociedades actuales, que abogan a una ciudadanía planetaria (Sant, Davies, Pashby y Shultz, 2018).

\subsection{Fragmentación histórica}

La evidente pluralidad historiográfica de los últimos años ha sido interpretada en numerosas ocasiones como negativa y referida desde el desorden (Fontana, 2013), el desequilibrio (Hernández, 2004) o como una situación insoportable que requería la "esperanza de la síntesis" (Burke, 1996, p. 35). Según Hernández (2004) la diversificación responde a las influencias de las diferentes ciencias sociales y sus metodologías propias. Para Aurell y Burke (2013b) surge de la reacción a los grandes relatos y la hiperespecialización de las ciencias sociales.

A pesar de la heterogeneidad, gran parte de las tendencias que surgen y se desarrollan en este contexto las relacionamos con el giro cultural de finales de siglo, fundamental para el desarrollo de tendencias como la nueva historia cultural, la nueva historia política (que recupera, entre otros, el género biográfico), la historia de la religiosidad, la historia social del lenguaje, la historia de la vida cotidiana o la historia de las emociones (Aurell y Burke, 2013b). De entre las diferentes tendencias desarrollas estos años y entendidas desde la fragmentación, hay algunas que destacan en las diferentes revisiones historiográficas. Tres de ellas nos interesan especialmente en la construcción de la historia de las personas y por el potencial que pueden tener al trasladarse a los contenidos y planteamientos de la historia escolar: la microhistoria, la historia vivida y la historia de las mujeres.

\section{a. Microhistoria}

La microhistoria se caracteriza por la reducción de la escala de observación, por el análisis microscópico de un entorno social y por el estudio intensivo de material documental, con gran importancia de lo simbólico (Levi, 1996). Se basa en la narración de hechos y protagonistas singulares con aspiraciones globalizadoras, ya que se pretende entender un contexto concreto a partir de experiencias singulares (Aurell y Burke, 2013b; Fontana, 2013). La reducción de escala permite revelar factores anteriormente no observados (Levi, 1996) así como entender las dinámicas reales de las relaciones sociales más allá de las estructuras rígidas de las clases sociales y sus espacios (Hernández, 2004). Según Levi (1996), permite una "descripción más realista del comportamiento humano (...) en un mundo que reconoce su relativa libertad más allá, aunque no al margen, de los sistemas prescriptivos y opresivamente normativos" (p. 121). Sin renunciar a tener en cuenta la diferenciación social, busca "descubrir las estructuras sociales de gran complejidad sin perder de vista (...) las personas y sus situaciones en la vida" (Levi, 1996, p. 122).

Las críticas a la microhistoria se han argumentado desde la imposibilidad de diferenciar lo importante de lo circunstancial (Fontana, 2013) y desde el cortoplacismo, la falta de proyección global y la falta de objetivos claros (Guldi y Armitage, 2016). Aun así, los aportes de esta corriente han sido fundamentales para entender las dinámicas reales de las relaciones sociales, para repensar los individuos y la comunidad, la agencia y la 
estructura, las vidas y las vivencias, y para aspirar a una abstracción que parta no de supuestos hipotéticos, sino de las experiencias humanas.

\section{b. Historia vivida / del presente}

La historia vivida (Aróstegui, 2004) se proyecta como una de las corrientes historiográficas más novedosas e influyentes de las últimas décadas de la mano de conceptos como los de experiencia histórica o memoria. Con el culto a la memoria se recupera una visión de las finalidades de la historia que considera que "la misión de la historia consistiría siempre en iluminar la condición humana a partir de los testigos de la memoria" (Hernández, 2004, p. 43). Para Hernández (2004), "el concepto de historia vivida (...) pugna por saltar en primer plano (...) a todo planteamiento en el que la vida misma de los individuos, sean éstos los que fueran, constituya el objeto general de estudio" (pp. 136-137).

La importancia de la historia oral en la historia vivida se vincula con la historia del presente reciente (Aurell y Burke, 2013b; Hernández, 2004). La inquietud por preservar la memoria de las personas antes de que mueran ha impulsado espacios y centros de investigación especializados en el almacenaje e interpretación de testimonios orales, así como una mayor preocupación por la vivencia histórica de procesos como los del exilio, la migración, las resistencias o la guerra. Esta preservación se vincula con la lucha contra las injusticias sociales porque permite reconocer la voz de todas las personas, democratizando los espacios de expresión. Por otro lado, da espacio a temas más vinculados a la vida, que frecuentemente permanecen ocultos, silenciados u oprimidos. Además, permite la recuperación experiencial de los sectores subalterizados y de experiencias coetáneas que rompen la falsa idea de la linealidad (Alderete, 2018).

\section{c. Historia de las mujeres}

La historia de las mujeres nace en confrontación con la historia que se había escrito hasta el momento -que había sido una historia masculina, autoproclamada como universal (herstory frente a la history) y reivindica espacios propios. Aurell y Burke (2013b) entienden que hay una primera fase centrada en la investigación sobre heroínas y pioneras de la emancipación femenina y la lucha feminista. Estas contribuciones no solo "situaron a las mujeres en las organizaciones políticas y los puestos de trabajo", sino que también "propusieron nuevos terrenos de acción, como la familia o los hogares, como temas dignos de estudio" (Scott, 1996, p. 75).

La posibilidad de normalizar la agencia histórica femenina en la concepción de un relato histórico común (ourstory) genera debate: muchas mantienen la necesidad de los espacios diferenciados para no volver a invisibilizar las experiencias particulares. La posibilidad del relato común coincide con la gran expansión temática y de abertura de visiones historiográficas, que entrarán en diferentes escenarios de la vida en los que mujeres y hombres de todas las edades y condiciones se entienden como sujetos y protagonistas. La visión crítica a la epistemología histórica parcial y patriarcal (y liberal, colonial y occidental, críticas que vendrán más adelante) cuestiona toda la construcción histórica hasta el momento. Si el conocimiento siempre se crea dentro de las relaciones de poder (Foucault, 2008), la historia de las mujeres implica un cuestionamiento de los puntos de vista que han puesto a los hombres como agentes principales y la modificación completa de la historia 
(Scott, 1996). Wiesner-Hanks (2008) considera que toda la historia de la humanidad pide de una revisión desde el punto de vista de las relaciones de género.

Durante estos años han aumentado los trabajos históricos -muchos de ellos biográficos- de recuperación de vidas, personalidades y experiencias de diferentes mujeres, una línea que sigue actualmente muy activa. Se recupera el tono reivindicativo e ideológico de la historia social de tendencia marxista que ha entendido la historia como un arma (Prieto, 1976) para combatir injusticias, desigualdades y exclusiones sociales.

Las perspectivas feministas historiográficas agrandan el impacto del giro cultural y otras tendencias historiográficas que permiten una visión más poliédrica de la sociedad y así como reinterpretar la importancia de lo privado, lo cotidiano, lo personal y lo vital, entendiendo lo personal como político (Greer, 1985). Las corrientes de la historia del cuerpo entienden que el control sobre el cuerpo se concibe como una forma de dominación política (Porter, 1996; Rivera Garretas, 2000). La historia de la vida (García Herrero, 2005) se fija en los ciclos, los nacimientos, las enfermedades, las muertes, la ternura, las violencias y la crianza: las dinámicas que sustentan la vida ya no son entendidas como curiosidades anecdóticas, sino como los elementos centrales de las dinámicas sociales y las vidas humanas. Si existe alguna posibilidad de planteamientos universales para todas las personas, se basaría en la capacidad de compartir las experiencias fundamentales de la vida: la muerte, el amor, el compromiso, la dignidad, el cuidado (Garcés, 2019).

En los últimos años las perspectivas feministas han entrado en diálogo con las perspectivas decoloniales. Ambas corrientes confluyen en la vindicación de presencias frente a la historiografía de las ausencias (Alderete, 2018) y por la deconstrucción ontológica sobre el conocimiento científico e histórico a partir de otras epistemologías. Para de Santos (2019) estas otras epistemologías han sido subvaloradas, eliminadas y perseguidas por la epistemología occidental hegemónica, articulada sobre los sistemas de opresión del colonialismo, el capitalismo y el patriarcado, y configuran una gran -y necesaria- riqueza de saberes sobre el mundo y cómo las personas y sociedades nos relacionamos con y en este.

La producción de la historia científica se articula sobre las dos funciones básicas de la corrección y el enriquecimiento (Sharpe, 1996). La pregunta por las personas ha contribuido a ambas. Ha llevado sin duda al enriquecimiento de nuevos conocimientos, temáticas, espacios y perspectivas. Pero también a la reinterpretación y profundización de algunos episodios y procesos con larga tradición y a una nueva comprensión de las causalidades a partir de la atención a sus protagonistas (véase, por ejemplo, Vuillard, 2019), sus estrategias (véase, por ejemplo, Rivera Garretas, 2017) y sus decisiones (véase, por ejemplo, Clark, 2016). También conlleva un importante cuestionamiento de interpretaciones largamente arraigadas, como la periodización tradicional, o conceptos como los de civilización, sociedad desarrollada o progreso. 


\subsection{Síntesis histórica}

Las corrientes de síntesis histórica o globalizadoras componen la segunda de las dos grandes tendencias de la historiografía actual (Aurell y Burke, 2013b). La producción historiográfica no ha abandonado nunca las perspectivas globalizadoras, que han vuelto a ser significativas durante la última década. Algunos autores identifican la crisis de la escritura de la historia universal con la incapacidad de los historiadores para gestionar la multiplicidad de los pasados humanos (Fillafer, 2017).

Los nuevos intentos de historia universal se han articulado, por un lado, a través de los planteamientos de la world history, que interpreta la historia de la humanidad de manera global, a partir de grandes periodos, incorporando lo que se conoce como deep history. Aunque los esfuerzos de abstracción son muy destacables, siguen reproduciendo en gran medida una evolución unilineal "que organiza las historias de los hombres en función del punto de llegada de la clase de presente impuesto por los pueblos europeos" (Fontana, 2013, p. 182).

El diálogo con otras ciencias no sociales se ha hecho evidente en algunas de estas obras de proyección global, que incorporan visiones e interpretaciones procedentes de la biología y la neurociencia. (véase, por ejemplo, Noah, 2014; Marina y Rambard, 2018). Para Aurell et al., (2013), la biohistoria es una de las tendencias que parece que pueden ganar fuerza en la corriente de la historia del medio ambiente como una de las novedades de la historiografía reciente (Hernández, 2004; Aurell y Burke, 2013b). Explora cómo nos relacionamos con el medio ambiente y se vincula con las proyecciones históricas de los estudios climáticos. Parece especialmente relevante dada la preocupación actual frente a la emergencia climática, y responde a la necesidad de encontrar en sociedades diferentes a las capitalistas posibles modelos para futuros alternativos (Guldi y Armitage, 2016). En este sentido destacan las obras de Diamond (2012; 2005), con alta proyección mediática.

La historia comparada es una de las maneras de enfocar la historia global en la actualidad, según Aurell y Burke (2013b). Fontana (2013) entiende que la comparación es una de las únicas formas de escape de la linealidad. Otra se trataría de la historia conectada, que se focaliza en las conexiones y las interacciones de personas y culturas (véase, por ejemplo, Gruzinski, 2011). Finalmente, encontraríamos las perspectivas globales de historias temáticas, que pueden abordar desde estructuras políticas a otras de más personales, como las emociones (Walton, 2005) o las experiencias íntimas (Zeldin, 1997), que pretenden proyectar una historia global de toda la humanidad a partir de procesos que entienden como universales. De hecho, esta proyección del universalismo es el principal problema que afrontan las proyecciones globales en la actualidad. Para Aurell y Burke (2013b), "el problema del punto de vista (...) se hace particularmente agudo en el caso de la historia mundial (...) zes posible contar la historia desde un punto de vista global?" (p. 332). Rüsen (2004) entiende que el etnocentrismo historiográfico se caracteriza por una evaluación asimétrica, una continuidad teológica y una perspectiva centralizada, contra las que propone la igualdad normativa, la reconstrucción de conceptos a partir de la contingencia y la discontinuidad, y la multiperspectiva y las aproximaciones policéntricas a la experiencia histórica. Para ello aboga a una nueva "culture of recognition" (p. 118). Fillafer (2017) defiende que "If we want to dislodge the structuring assumptions connected with 
globality, interrogating the premise that the world has one history is a good way to start" (p. 37).

Las tendencias globalizadoras nos dejan la sensación que no aprovechan los avances de la investigación ni del repensar epistemológico de los últimos años, ya que, en la mayoría de los casos, se construyen sobre las ideas tradicionales del progreso lineal eurocéntrico, ahora renovado con aportaciones biológicas y de la neurociencia. En el necesario -aunque complicado- juego de escalas entre lo micro y lo macro, la construcción de una historia que haga abstracción para proyectar el conjunto de la humanidad a partir de todas las personas, sus experiencias y los diferentes espacios y dimensiones de la vida humana que han recogido las investigaciones históricas de los últimos años, está aún por escribir.

\section{Apuntes sobre la evolución de la historia escolar}

No nos es posible conocer cómo se enseña y se aprende la historia escolar en su totalidad, ya que las prácticas educativas dependen de los contextos irrepetibles que se viven en las aulas, de las experiencias del alumnado y de las decisiones que toman las profesoras y profesores. La investigación en DCS se pregunta por los diferentes elementos didácticos y la relación entre ellos: el alumnado y los procesos de aprendizaje, el profesorado y los procesos de enseñanza, los contenidos y materiales, y la relación con metodologías y contextos. En el apartado que sigue hacemos algunos apuntes sobre cómo la investigación en didáctica de las ciencias sociales se pregunta por las personas que protagonizan la historia escolar (apartado 5.1). Nos detenemos también en el análisis del currículum español (apartado 5.2) entendiendo que este es el marco oficial de referencia, compartido, sobre el que se toman las decisiones educativas concretas. Sirve también de referencia para analizar las coherencias e incoherencias con los avances historiográficos y las implicaciones de las políticas educativas.

\subsection{Evolución de la investigación en didáctica de las ciencias sociales}

La didáctica de las ciencias sociales es una ciencia relativamente nueva. En estos 25 años ha pasado de estar en una fase inicial de construcción teórica a consolidarse como comunidad científica con modelos, conceptos y líneas de investigación compartidas (GómezCarrasco, López-Facal y Rodríguez-Medina, 2019), a través una producción científica notable en las últimas décadas (Henríquez y Pagès, 2004; Lautier y Allieu-Mary, 2008; Plá y Pagès, 2014).

En el caso de la historia escolar, se han hecho aportaciones fundamentales en aspectos como el aprendizaje de la temporalidad, la comprensión de situaciones sociales actuales a partir de la problematización del cambio y la continuidad, los diferentes aspectos que conforman el pensamiento histórico (Lévesque y Clark, 2018; Seixas, 2017) ○ el desarrollo de la conciencia histórica (Rüsen, 2005; Seixas, 2017). Pero cuando nos preguntamos por las personas que protagonizan los contenidos socio-históricos, la exclusión de personas y grupos es una cuestión no resuelta (Jara y Santisteban, 2018).

Podemos ubicar las investigaciones sobre la centralidad y el papel de las personas en los contenidos de la historia escolar en tres áreas principales. Por un lado, (1) las que refieren 
al estudio de las personas que protagonizan los contenidos desde la presencia y la ausencia de personas y colectivos concretos, y que se preguntan sobre las exclusiones sociales perpetradas a través de las invisibilidades históricas y curriculares. Por otro, (2) las que se preguntan por las identidades, la multiculturalidad, la diversidad o la inclusión social a través del currículum. Finalmente, (3), las investigaciones sobre la agencia histórica, que forma parte de los planteamientos sobre pensamiento histórico en la comprensión de las causalidades y las consecuencias, el cambio social y la empatía. Estos tres campos están estrechamente relacionados y se entrecruzan en muchos de sus planteamientos. Aun así, los presentamos por separado para poder ubicarlos de manera más clarificadora.

\section{a. Las presencias y las ausencias}

Villalón y Pagès consideraban en 2013 que la investigación histórica había hecho grandes avances en la diversificación de actores y protagonistas históricos, pero que no podía decirse lo mismo del currículum oficial y los libros de texto:

La enseñanza de la historia ha incorporado aspectos tan importantes como la conciencia histórica, la temporalidad, la memoria histórica, el patrimonio...sin embargo se ha dejado de lado el debate sobre los protagonistas más allá del debate relacionado con las historias nacionales o con los grupos de presión que, en algunos países, tienen poder para incluir su presencia en los currículos (Villalón y Pagès, 2013, p. 121).

Para Matozzi (2015), incluso en los casos en los que se han incorporado sujetos, espacios y temáticas diferentes a las de la historia escolar tradicional en los manuales, se han introducido como elementos secundarios supeditados al relato geopolítico y los protagonistas dirigentes.

GREDICS, grupo de investigación de la Universidad Autónoma de Barcelona, del que formamos parte los autores del presente artículo, desarrolla desde hace años una línea de investigación centrada en las personas protagonistas y las personas invisibilizadas en las ciencias sociales escolares. Por otro lado, la Asociación Universitaria de Profesorado de Didáctica de las Ciencias Sociales (AUPDCS) dedicó en 2015 una edición de los simposios anuales a las personas, temáticas y lugares invisibles en las ciencias sociales. Muchas de las investigaciones se han centrado en las presencias y ausencias de colectivos concretos, sobre todo mujeres, grupos étnicos y niños y niñas, y se han considerado como colectivos invisibilizados aquellos que no tienen representación en los contenidos curriculares (Massip y Castellví, 2019).

En España contamos con un corpus extenso de investigaciones y propuestas sobre la ausencia de las mujeres en los contenidos escolares, en las representaciones del alumnado, en las prácticas docentes y en espacios educativos no formales (museos, por ejemplo). La aplicación de la perspectiva de género en las líneas de investigación de DCS se ha ido consolidando durante los últimos 15 años (Díez y Fernández, 2019). En cambio, faltan investigaciones sobre otros ejes de identidad infrarrepresentados en los contenidos históricos, pero con presencia social destacable en el estado, como la comunidad gitana en el eje cultural, las personas homosexuales en el eje de orientación sexual, entre muchas otras. 
La invisibilidad curricular se considera como una forma de violencia (Solsona, 2019). Para Maldonado-Torres (2007), la invisibilidad va de la mano de la deshumanización. Para Santos (2019), forma parte de las estrategias de dominación y de opresión de personas, colectivos y formas de vida, y de la maquinaria de producción de la inexistencia. Para este autor, la invisibilidad, la irrelevancia y la no existencia conforman las ausencias, unas ausencias que responden a mecanismos para convertir "ciertos grupos de personas y formas de vida social" en "no existentes, invisibles, radicalmente inferiores o radicalmente peligrosos; en suma, descartables o amenazadores" (Santos, 2019, p. 53).

\section{b. Diversidad e identidades}

La falta de diversidad de las personas que protagonizan los contenidos sociales no es sólo un problema curricular. Algunos estudios apuntan que la falta de identificación con los contenidos y sus protagonistas es una de las causas -aunque no la única- de desmotivación del alumnado y de desvinculación escolar, relacionada con el abandono prematuro de los estudios (Yuste y Monéjar, 2017). Los contenidos sociales escolares, especialmente los históricos y geográficos, tienen gran influencia en la construcción de las identidades individuales y colectivas. La preocupación por la construcción de un aprendizaje no excluyente de las ciencias sociales escolares, y de los contenidos históricos especialmente, es generalizada a diferentes partes del mundo. Para Tutiaux-Guillon (2018), lo que hay es la necesidad de reconocer la pluralidad, y que los contenidos escolares contribuyan a ello, sobre todo en espacios de diversidad cultural.

Estas cuestiones toman especial relevancia en espacios donde conviven comunidades indígenas y first nations con comunidades occidentalizadas, como en los casos de Canadá, Estados Unidos, Colombia, Chile, Perú, Brasil, Argentina, entre otros países americanos, o de Nueva Zelanda. En estos casos se hace aún más evidente la necesidad de plantear no sólo las presencias y ausencias de personas y colectivos, sino también la transformación de las temáticas y las perspectivas, en un proceso que puede ir desde la inclusión hasta la transformación y la acción educativa (Kanu, 2005). Para Carlson (2010), requiere incluso un replanteamiento de conceptos como los de conciencia histórica o pensamiento histórico, ya que nacen de las concepciones universalistas eurocéntrias en la manera de relacionarnos con la temporalidad, el pasado o la memoria. Según Seixas (2017) "it is a call to entertain plural standards of truth, and to accord multiple understandings of the relationships about past, present and future" (p. 68). En este sentido, existen debates importantes sobre la necesidad de crear relatos comunes y la de mantener espacios propios de singularidad (Sabzalian, 2019).

\section{c. Agencia histórica}

Defender la relevancia de todas las personas, sin exclusiones, puede parecer más sencillo en la proyección del presente y el futuro que en la proyección a las personas del pasado. Como hemos visto, la democratización de la agencia histórica y la reconsideración del papel de las personas que habían sido excluidas como sujetos históricos en la producción historiográfica tradicional cuenta con pocas décadas de tradición historiográfica -y sigue en desarrollo. En el ámbito de la historia escolar esta democratización es aún más lenta, y se encuentra con resistencias diversas. Aun así, durante estos últimos 25 años el concepto de 
la agencia histórica se ha ido consolidando y ubicando en los planteamientos del pensamiento histórico y en relación a conceptos como los de causas y consecuencias, cambio social o empatía (Den Heyer, 2018).

Ya a las puertas del periodo estudiado, Seixas (1993) defendía que la formación de la ciudadanía se complicaba sin el concepto de agencia histórica: "without this tool, students cannot see themselves as operating in the same realm as the historical figures (...) and thus cannot make meaning out of history" (p. 303). Así, la agencia histórica refuerza dos aspectos básicos: por un lado, las explicaciones sobre las causalidades y las explicaciones sobre el cambio social, y por otra, la comprensión de las propias capacidades como agentes de la vida social (Den Heyer, 2003).

La agencia histórica se ha abordado tanto desde las investigaciones sobre las causalidades, como desde aquellas que se focalizan en el cambio social (Den Heyer, 2003). Para Den Heyer (2003), para la enseñanza de la historia es necesaria una reflexión explícita sobre las maneras en las que la agencia humana produce cambios sociales, cambios históricos. Señala que, a lo largo de estos años, desde la enseñanza de la historia se ha preferido asignar causas a ciertos hechos históricos que analizar las interpretaciones sobre la agencia histórica (Pomper, 1996; Seixas, 1996; Shaw, 2001; en Den Heyer, 2018).

Años antes de conceptualizar los elementos del pensamiento histórico y del impacto internacional de su propuesta, Seixas (1993) planteaba una tríada conceptual entre la agencia histórica, la empatía histórica y el juicio moral. En esta entendía que la empatía "should be exercised to understand historical figures as agents who faced decisions, conflicts, constraints and hardships under circumstances and with ways of thinking quite different from our own" (p. 303). La relación entre la agencia histórica y la empatía es innegable, aunque esta segunda ha tenido un recorrido conflictivo en el área. La empatía histórica ha sido una idea criticada y contestada; aun así, a lo largo de estos años se ha avanzado en su investigación y conceptualización (Endacott y Brooks, 2018). En el marco de una empatía contextualizada, es frecuente el planteamiento de dilemas en la toma de decisiones de personas concretas. Pero estas siguen recayendo, mayoritariamente, sobre protagonistas pertenecientes a élites políticas y económicas, reproduciendo una idea de agencia histórica individual y elitista. Seixas (2012) identifica esta limitación de los protagonistas agénticos a las élites políticas y nacionales con la pedagogía histórica de la submisión. Para Endacott y Brooks, los futuros estudios sobre la empatía tendrán que incorporar

A more pluralistic approach to the types of historical figures that students are invited to empathize with. What a unique challenges and opportunities present themselves when students are asked to explore the perspectives and experiences of those who are frequently marginalized by traditional history curriculum? (2018, p. 221).

Nos parece destacable, en este sentido, que buena parte de la literatura referente a la empatía histórica y a la agencia histórica usa expresiones como personajes históricos o figuras históricas, conceptos que a nuestro entender deshumanizan las personas y que juegan en contra tanto del trabajo de la empatía como de la comprensión de la agencia humana. Algunas investigaciones destacan la visión individualista que el alumnado tiene de 
la agencia histórica (Arias-Ferrer y Egea-Vivancos, 2019; Den Heyer, 2018), así como la consideración de agente e incluso sujeto a elementos no humanos como estados o países los casi-personajes de Ricoeur (1995) -. En este sentido parece importante poder enfatizar, en la enseñanza de la historia, una doble perspectiva que parece redundante: que los agentes de la historia somos personas; y que todas las personas somos agentes sociales, de cambio y continuidad $y$, por tanto, agentes históricos.

\section{d. Historia oral y patrimonio: recursos emergentes para la historia de todas las personas}

Son muchos los recursos y estrategias desarrollas para trabajar unos contenidos sociohistóricos escolares que se pregunten por todas las personas protagonistas y que partan de los problemas y realidades de las personas: el trabajo con fuentes (Pagès y Santisteban, 1994), el trabajo a partir de cuestiones controvertidas (Legardez y Simmoneaux, 2006) o los planteamientos diacrónicos y transtemporales (Dawson, 2004), entre otros. Explicamos brevemente dos recursos que nos parecen especialmente interesantes en el desarrollo del pensamiento histórico, la comprensión de las múltiples perspectivas, y la identificación del alumnado como agentes sociales e históricos.

El trabajo con la historia oral es un recurso que se ha identificado como importante en el desarrollo del pensamiento histórico, la significación de los aprendizajes y la conexión e identificación del alumnado con aquello que aprende. Permite, además, abrir debates sobre la relación entre la historia, la memoria y la experiencia (Meneses, González-Monfort y Santisteban, 2020) y reconocer que el propio pasado y el pasado familiar es una parte importante de la historia (Levy, 2016). Se hace especialmente complejo -e interesante- en regiones con conflictos históricos recientes, vivenciados personalmente $\circ$ por familiares (Savenije, van Boxtel y Grever, 2014). Para Levy (2016), llevar al aula la historia difícil en zonas de postconflicto favorece el pensamiento histórico complejo y el compromiso y empatía con diferentes personas y sus historias. En este caso, el desarrollo de la empatía es importante también para la comprensión de la racionalidad histórica (entender las causas y las ideologías), ya que una de las mayores dificultades del alumnado que aprende contenidos históricos es entender por qué las personas de aquel momento hicieron lo que hicieron (Kitson et alt. 2015).

La educación patrimonial se ha identificado, en algunos países como Holanda, como una de las claves para diversificar las personas protagonistas y permitir debates sobre las diferentes perspectivas y vivencias de determinados procesos históricos. Para De Brujin (2011, en González-Valencia, Massip y Castellví, 2020), los elementos patrimoniales públicos son reconstrucciones simbólicas limitadas porque solo interpelan a unas personas determinadas, mostrando una clara falta de pluralidad. Fontal e lbáñez (2015) defienden que los elementos patrimoniales representan uno de los recursos más importantes para una educación no excluyente y orientada a la inclusión social desde la accesibilidad y la identidad: todo el mundo tendría que poder acceder a ellos, y todo el mundo tendría que poder identificarse con ellos.

Savanije (2011) propone el trabajo educativo con el patrimonio difícil para crear narrativas abiertas que generen múltiples perspectivas e inclusión. La comprensión de estas multiperspectivas y los diferentes puntos de vista se han identificado como esenciales para 
el desarrollo del pensamiento crítico (Lewison, Flint y Van Sluys, 2002). Las propuestas de trabajo de la literacidad crítica también incluyen la pregunta por las personas que aparecen y las que no, por quiénes son los que se benefician de unas ideas determinadas y quienes quedan perjudicados, y por la detección de silencios y silenciados.

La comprensión de las complejidades en las conductas y las relaciones humanas del pasado se ha relacionado con la disposición a cuestionar las generalizaciones y las desigualdades sociales en el presente (Kitson et alt., 2015). Del mismo modo, entender que las personas del pasado fueron agentes activos a pesar de las diferencias de contextos y circunstancias, influye en la comprensión de la importancia de las acciones colectivas en el cambio histórico (Arias-Ferrer y Egea-Vivancos, 2019) y en la aceptación de la propia condición de agente social (Massip y Pagès, 2016).

\section{e. Cambiar las prácticas}

La no consideración de todas las personas como protagonistas de los contenidos de la historia escolar se detecta como un problema en los diferentes ámbitos de investigación de los que hemos hablado. Se constata que los contenidos sociales e históricos escolares siguen anclados en narrativas nacionales con enfoques únicos (Den Heyer, 2018; López, 2015). No dan respuesta a la complejidad social, a los retos y preocupaciones actuales, a las necesidades educativas del alumnado, ni a la formación de una ciudadanía crítica. Tampoco incorporan los avances historiográficos ni dan una visión completa de la sociedad. Los resultados de varias investigaciones nos indican que en muchas aulas los contenidos reproducen desigualdades y valores nacionales, eurocéntricos y androcéntricos que excluyen gran parte de la población (Marolla, 2017; Pagès y Sant, 2002). El currículum oficial y las prácticas tradicionales de la historia escolar, entre otras, dificultan el cambio de las prácticas y los contenidos (Marolla, 2016; Massip, en prensa).

Las investigaciones nos sugieren que la formación historiográfica del profesorado no es determinante en las decisiones que toma el profesorado sobre qué contenidos históricos enseñar (Guimerá, 1992). Por contra, serían las propias opiniones y concepciones sobre lo que es importante enseñar, la voluntad de dar respuestas a las necesidades del aula o la voluntad de conectar con el alumnado lo que en muchas ocasiones lleva al profesorado a innovar los contenidos históricos del aula. Los contenidos históricos que se enseñan y aprenden dependen de cada contexto irrepetible y de las decisiones que toma el profesorado sobre el currículum. Como apuntan Kitson, Steward y Husbands (2015, p. 49), "el principal recurso para el aprendizaje, el recurso del que depende todo lo demás, es el profesorado". Para Pagès (2019), la práctica educativa solo cambia cuando el profesorado está dispuesto a hacerlo. Y una vez ha decidido que quiere cambiar, se le hace imprescindible poder disponer de herramientas (conocimientos, estrategias, materiales) para materializarlo (Massip, en prensa). 


\subsection{Evolución del currículum oficial}

La base común sobre la que el profesorado ha de tomar decisiones se establece en los currículums oficiales. En los últimos 25 años hemos vivido en España tres leyes educativas (LOGSE, LOE y LOMCE) y sus respectivos reales decretos que han marcado el currículum educativo oficial. La entrada en vigor de la Ley Orgánica General del Sistema Educativo el 1990 sucedía a la consolidación de la didáctica de la historia y de las ciencias sociales en España de los años ochenta (Pagès y Santisteban, 2014). Analizando los reales decretos que establecen el currículum de educación primaria y de secundaria (Real Decreto 1006/1991 y Real Decreto 1345/1991 respectivamente) identificamos que los contenidos se organizan en conceptos, procedimientos y actitudes. En la educación primaria, la enseñanza de la historia, dentro de la asignatura de conocimiento del medio natural, social y cultural se articula a partir de la relación de hechos considerados como relevantes para la historia nacional, con la cotidianidad del alumnado. Los procedimientos inciden en el uso de las fuentes históricas y la elaboración de ejes cronológicos y las actitudes inciden en la valoración y el respeto del patrimonio y de la historia, como un producto humano en el que las personas somos sujetos activos. Sin embargo, los criterios de evaluación establecen, además de la capacidad de recoger información, "ordenar temporalmente algunos hechos históricos" (Real Decreto 1006/1991, p. 7) ○ "describir algunos aspectos de la vida cotidiana de las personas [...] en las principales etapas históricas de la humanidad" (p. 7).

El currículum para la educación secundaria favorece una educación transmisiva y memorística de los hechos históricos. Así, en el apartado de sociedades históricas se desarrolla un contenido cronológico para la enseñanza de la historia. La historia que se presenta es la de los grandes hechos y acontecimientos, y es casi totalmente eurocéntrica. El apartado llamado sociedad y cambio en el tiempo aborda temas como el cambio social en la época contemporánea y "aspectos significativos de la vida humana" (Real Decreto $1345 / 1991$, p. 5) como los rasgos de la actividad económica, de la vida privada y la marginación femenina, de las creencias religiosas, de la forma de organización social y política, etc. Los procedimientos más destacados para esta etapa son el tratamiento de la información y la explicación multicausal, mientras que la actitud apuntada es el rigor crítico y la curiosidad científica. El apartado octavo, titulado participación y conflicto político en el mundo actual se centra en la enseñanza de las instituciones nacionales como la Constitución, la organización territorial o los partidos políticos como vehículos de la participación social.

La Ley Orgánica de Educación (2006) incorpora el aprendizaje competencial o por competencias, de entre las que destacamos la competencia social y ciudadana, y las asignaturas de educación para la ciudadanía y los derechos humanos, en educación primaria y secundaria, y educación cívico-ética en el cuarto curso de la educación secundaria. Para los contenidos de educación primaria (Real Decreto 1513/2006) destacamos los bloques personas, culturas y organización social y cambios en el tiempo. Estos bloques de contenidos parten de la cotidianidad del alumnado, pero incluyen elementos como la lucha contra los estereotipos sexistas y el reconocimiento de la diversidad cultural. En relación con los hechos históricos podemos leer "algunos acontecimientos del pasado y del presente y su relación con aspectos históricos cercanos a su experiencia" o "identificación del papel de los hombres y las mujeres en la historia". Los criterios de evaluación son consecuentes con los contenidos, pero se centran en "ordenar temporalmente algunos hechos 
relevantes de la vida familiar o del entorno próximo" (p. 43065). Los contenidos en el ciclo superior (9-12 años) son más disciplinares y se centran en la caracterización de algunas sociedades de épocas históricas y acontecimientos y personajes considerados relevantes de la historia de España. Este hecho parece evidenciar que la conexión de la historia con el presente y con la cotidianidad es una forma de introducir el conocimiento que se considera relevante en cursos posteriores, que es el de los hechos y personajes históricos relevantes para el país.

La tendencia a la disciplinaiedad se hace evidente en el currículo de secundaria (Real Decreto 1631/2006). El contenido es totalmente disciplinar y repasa de manera cronológica las diferentes etapas, empezando por la prehistoria y terminando por el mundo actual. Además, los criterios de evaluación establecen que el alumnado debe saber identificar, situar, exponer, caracterizar o diferenciar los diferentes hechos históricos como un objetivo en sí mismo. Solo se establecen relaciones entre la historia y el presente de forma muy superficial en el último apartado del cuarto curso. Por contra, la asignatura de educación para la ciudadanía y los derechos humanos, junto con la asignatura de educación ético-cívica, sí incluye en sus objetivos los que entendemos que deberían ser los de la enseñanza de cualquier ciencia social, incluida la historia. En educación para la ciudadanía y los derechos humanos, destacamos el bloque de contenido ciudadanía en un mundo global, que incluye un mundo desigual: riqueza y pobreza, o el bloque de contenido de educación ético-cívica problemas sociales del mundo actual.

En la actualidad, el currículo vigente es el de la Ley para la Mejora de la Calidad Educativa (2013) que fue aprobada por el gobierno del Partido Popular de Mariano Rajoy. Esta ley, a través de los reales decretos correspondientes (Real Decreto 126/2014 y Real Decreto $1105 / 2014$ ) elimina la asignatura de educación para la ciudadanía y los derechos humanos, pero mantiene el carácter disciplinar de los bloques de historia, también para primaria, eliminando las referencias a la cotidianidad y a la experiencia histórica del alumnado que se daban en los primeros ciclos. Se crea una asignatura de valores sociales y cívicos que nada tiene que ver con la del currículo anterior. Del contenido de esta destacamos estándares de aprendizaje evaluables como "razonar la importancia de la iniciativa privada en la vida económica y social" (p. 56) o conocer y expresar las notas características de la democracia y la importancia de los valores cívicos en la sociedad democrática, así como el significado de los símbolos nacionales, la Bandera, el Escudo de España y el Himno nacional como elementos comunes de la Nación española y el conjunto de los españoles.

Para secundaria, el currículo es disciplinar y más detallado que en la ley anterior, especificando qué elementos de cada época es preciso trabajar. No es hasta el bloque de contenido octavo, para el último año de la educación secundaria obligatoria, que se incluyen algunos elementos que relacionan pasado y presente. Con todo, los temas tratados en la contemporaneidad se reducen a la globalización, poniendo énfasis en su vertiente económica, y la revolución tecnológica, omitiendo los problemas sociales globales a los que nos enfrentamos como individuos y como sociedad. Solo el bloque último expresa la necesidad de comprender que el pasado "no está muerto y enterrado, sino que determina - influye en el presente $y$ en los diferentes posibles futuros y en los distintos espacios" (p. 304). 
Este análisis evidencia que, si bien el panorama educativo ha cambiado, no lo ha hecho el currículo de manera significativa. La investigación continúa sin ser una fuente de información para la elaboración del currículo de historia. El aprendizaje memorístico, disciplinar y transmisivo sigue siendo prioritario (Pagès y Santisteban, 2014). Algunas ideas de la conciencia histórica y los elementos más significativos del pensamiento histórico se han introducido levemente en el currículum oficial -sobre todo en las concreciones curriculares de algunas comunidades autónomas, no analizadas en este trabajo-, pero están lejos de ser la base sobre la que se estructura. Por el contrario, los avances realizados tanto desde la historiografía como desde la didáctica de las ciencias sociales en la diversificación de agentes y protagonistas históricos o en la articulación de temáticas más centradas en las experiencias y problemas humanos que en la geopolítica nacional, no han tenido un impacto destacable en los planteamientos curriculares.

\section{Reflexiones finales y retos de futuro}

\subsection{Síntesis}

En este artículo hemos tratado de entender cómo han evolucionado la historia académica y la historia escolar a lo largo de estos últimos 25 años en relación a la proyección de una historia de las personas. Es decir: una historia que reconozca todas las personas como agentes sociales e históricas y que se centre en las experiencias de vida.

Hemos diferenciado la historia escolar de la historia académica, así como la investigación historiográfica de la investigación en didáctica de la historia y en didáctica de las ciencias sociales, entendiendo que responden objetivos, métodos y contextos distintos.

La historiografía de los últimos 25 años ha vivido un proceso de gran diversificación. Durante la última década las tendencias de síntesis han ido ganando peso. Entendemos que más allá de la diversificación y la heterogeneidad, la historiografía de estos años se caracteriza por 1) la hegemonía de la nueva historia cultural y la visión holística e integradora que proyecta de la cultura; 2) el redescubrimiento de la narración; 3) el interés por temáticas relacionadas con la experiencia humana y obviadas durante las décadas anteriores; 4) la democratización de la agencia histórica y la atención a las dinámicas sociales micro para entender las relaciones sociales y las dinámicas de cambio social; 5) la aceptación de la subjetividad de la persona historiadora, y 6) la influencia de la antropología, las teorías feministas y las decoloniales en la vindicación de las personas, las experiencias y las formas de vida obviadas por la historiografía tradicional y que pueden servir a la búsqueda de relaciones y modos de vida alternativos. De las tendencias de diversificación hemos destacado la microhistoria, la historia de las mujeres y la historia vivida o del presente como aportes transcendentes en el poder plantear una historia de las personas. De las tendencias de síntesis destacamos el esfuerzo por entender la humanidad de manera global. La proyección de interpretaciones a gran escala permite reflexiones sobre la humanidad como conjunto, sobre cómo las personas vivimos, nos relacionamos y nos organizamos, pero de manera mayoritaria se reproducen esquemas lineales, patriarcales y eurocéntricos, que no aprovechan los avances de la investigación historiográfica referenciada. Estos quedan diseminados en estudios, tendencias y escuelas, pero no integrados en síntesis de comprensión global. 
La didáctica de las ciencias sociales es una ciencia que se ha ido consolidando a lo largo de estos 25 años. En relación a la historia escolar, se ha investigado y teorizado ampliamente sobre temas como el tiempo histórico, el pensamiento histórico o la conciencia histórica. Identificamos sobre todo tres líneas de investigación que se preguntan por las personas que protagonizan los contenidos históricos, sus roles y espacios: las que analizan las presencias y la ausencias de personas y colectivos concretos; las que se centran en las identidades, la convivencia y la diversidad; y las centradas en la agencia histórica. A pesar del desarrollo de estas líneas de investigación, los planteamientos curriculares oficiales siguen anclados en una historia geopolítica y nacional protagonizada por personajes procedentes de élites políticas y económicas que se identifican como agentes activos. El análisis del currículum oficial confirma que ni los avances en la didáctica de las ciencias sociales ni los avances historiográficos no tienen impacto significativo en su desarrollo. De manera general, la historia escolar sigue reproduciendo desigualdades sociales a partir de valores androcéntricos, eurocéntricos, nacionales y liberales.

\subsection{Retos}

Consideramos que el hecho que las personas no sean centrales en el desarrollo temático de la historia escolar y que protagonicen sus contenidos una minoría social privilegiada es un problema educativo importante. En primer lugar, porque unos contenidos sociales que no contemplan la totalidad de la sociedad son unos contenidos incompletos. En segundo lugar, porque no están actualizados científicamente. Además, porque reproducen desigualdades a través una pedagogía de la sumisión (Seixas, 2012), precisamente en un contexto de extrema residualización y discriminación social (Bauman, 2011; Garcés, 2019; Santos, 2019). Finalmente, porque no da respuesta a las necesidades y realidades del alumnado: ni a sus vidas, ni a la complejidad social en la que viven, ni a la comprensión de su propia agencia $y$, por tanto, de su lugar en el mundo.

Entendemos que tanto la historia académica como la historia escolar comparten el reto de escribir y enseñar una historia de todas las personas y que parta de las realidades humanas. La multiperspectiva y la reflexión empática sobre las acciones y las circunstancias de las personas se han identificado como claves tanto en la historia científica como en la escolar.

Para lograrlo, quizá uno de los retos más importantes de la historia escolar es el de sobreponerse a un currículum oficial caracterizado por un "sentido teleológico y positivista de la historia patria" (Rina y de la Montaña, p. 287). El reto no es menor: que el currículum responda a criterios educativos y no a presiones políticas. Creemos que la solución va en la dirección de entender el currículum como no prescriptivo y que éste se desarrolle desde abajo, con participación del profesorado, y actualizado científicamente reconociendo los avances de la historiografía y de la didáctica. De la Montaña, (2015) entiende que visibilizar temas y colectivos sociales en la historia escolar pasa por apostar por corrientes historiográficas completas y complejas y desechar aquello que se entienda que no ayuda a proponer una historia integradora y no excluyente.

Es necesario que los contenidos históricos dejen de ser discriminatorios y reproductores de desigualdades, que incluyan y reconozcan a todas las personas como agentes, como 
protagonistas, que ayuden a entender el presente y que transformen los relatos para que conecten con la vida, con las vidas. Para Kitson, Steward y Husbands, el profesorado no ha de perder los relatos menores de la historia y moverse entre las visiones de conjunto y los relatos personales, para cautivar el interés de los alumnos y para "ayudarles a entender lo que estaba pasando realmente a un nivel humano (2015, p. 166). La evolución historiográfica ha generado suficiente conocimiento durante los últimos años para poder optar por este tipo de contenidos. Creemos que uno de los retos de futuro también es el de repensar la comunicación entre la historia científica y la escolar.

En el campo de la didáctica de las ciencias sociales, Jara y Santisteban (2018), entienden que se afrontan 10 retos para el futuro: (1) Repensar por qué enseñamos ciencias sociales; (2) re-humanizar la enseñanza y educar para la justicia social; (3) educar para la ciudadanía democrática global; (4) enseñar ciencias sociales a partir de cuestiones socialmente vivas; (5) formar el pensamiento social; (6) visibilizar a personas, identidades y grupos sociales invisibles; (7) investigar el papel de las emociones en el aprendizaje de las ciencias sociales; (8) construir relatos para la diversidad y la convivencia pacífica; (9) enseñar a participar y educar para el futuro; y (10) formar al profesorado como intelectuales críticos.

En el caso de la historia científica, para Guldi y Armitage (2016) el reto es recuperar la misión pública con proyección de futuro. Consideran fundamental aplicar perspectivas trasnacionales y trastemporales para "combatir el cortoplacismo de nuestros días" con la "amplitud de ángulo y la visión de largo alcance" (p. 227). Para hacerlo piden la articulación entre lo micro y lo macro a través de la construcción de macrorrelatos que respondan a los problemas del presente a partir de microhistorias que ayuden a "desestabilizar las explicaciones heredadas acerca de la inevitabilidad del imperio, la centralización, el capitalismo o la jerarquía" (p. 218). En este sentido, una de las mayores funciones del conocimiento histórico sería -y coincidimos con ellos- recuperar experiencias y modelos alternativos que nos sirvan de inspiración para poder imaginar "futuros alternativos posibles" (p. 73). Algo que Santos (2019) refiere como ruinas-semilla: aquellos modelos del pasado que, aunque desaparecidos o destruidos, siguen presentes en la memoria y permiten proyectar alternativas de futuro.

Dar presencia a estas otras maneras de vivir, diferentes a las que finalmente han triunfado - que son hegemónicas ahora mismo, es también el reto que plantean las personas que defienden las perspectivas decoloniales, feministas y subversivas. Requiere, pues, hacer la abstracción a partir del reconocimiento y la dignificación de todas las personas y de todas las experiencias humanas. Como defiende Fontana (2013, p. 191):

Una nueva historia total deberá ocuparse de todos los hombres y mujeres en una globalidad que abarque tanto la diversidad de los espacios y las culturas como la de los grupos sociales (...). Habrá que renunciar al eurocentrismo y prescindirá, en consecuencia, del modelo único de evolución humana con sus concepciones mecanicistas del progreso, que aparece como el producto fatal de las "leyes de la historia", con muy escasa participación de los humanos, que deberían ser sus protagonistas activos. 
La tarea no es sencilla; este tipo de historia está aún por escribir. Pero Fontana (2013) nos deja algunas líneas sobre cómo tendría que desarrollarse: En primer lugar, a través de una forma que abandonara la narrativa y optase por un tipo de relato polifónico que trabajase con historias de vida y "que escogiese el número suficiente de las voces altas y bajas, grandes y pequeñas, de la historia para articularlas en un coro más significativo" (Fontana, 2013 , p. 192); por otro lado, a partir de acontecimientos concretos y no de soluciones preestablecidas; y finalmente, abandonando la linealidad "que nos ayudará no solo a superar el eurocentrismo, sino también el determinismo (p. 195).

Tanto la ciencia histórica como la historia escolar comparten, desde esta perspectiva, un mismo reto: el de dignificar las personas y ahondar en la comprensión de las sociedades humanas para que podamos dar forma, con nuestras acciones, a un futuro más justo. Un futuro que, según Fontana (1997), no está determinado, sino que será el resultado de los que todos nosotros sepamos y queramos hacer.

\section{Bibliografía}

Alderete, P. F. (2018). For a historiography of the "absences": the lived experience and the historical present as fundamental categories for the study of Latin American peasant subalternity. Historia da Historiografia, 28(11), 141-165.

Apple, M. (1991). Ideología y currículo. Madrid: Akal.

Aragon, S. (2000). El señor ausente. El señorío nobiliario de la España de los setecientos. Mateos: Editorial Milenio.

Arostegui, J. (2004). La historia vivida. Sobre la historia del presente. Madrid: Alianza Editorial.

Arias-Ferrer, L. y Egea-Vivancos, A. (2019). Who changes the course of history? Historical agency in the narratives of Spanish pre-service primary teachers. History Education Research Journal, 16(2), 322-39. doi: 10.18546/HERJ.16.2.11

Aurell, J., Balmaceda, C., Burke, P. y Soza, F. (2013). Comprender el pasado. Una historia de la escritura y el pensamiento histórico. Madrid: Akal.

Aurell, J. y Burke, P. (2013a). De entresiglos a la década de los setenta: la reacción frente al positivismo. En J. Aurell, C. Balmaceda, P. Burke y F. Soza (eds.), Comprender el pasado. Una historia de la escritura y el pensamiento histórico (pp. 237-286). Madrid: Akal.

Aurell, J. y Burke, P. (2013b). Las tendencias recientes: del giro lingüístico a las historias alternativas. En J. Aurell, C. Balmaceda, P. Burke y F. Soza (eds), Comprender el pasado. Una historia de la escritura y el pensamiento histórico (pp. 287-240). Madrid: Akal.

Baldó, M. (2009). Introducció a la història. Praxi, estructura i canvi. València: PUV

Ballbé, M. (2019). Els i les mestres com a responsables del currículum. El cas del grup de mestres de ciències socials de segona etapa d'EGB de Rosa Sensat. Tesis Doctoral. Bellaterra: Universitat Autònoma de Barcelona. 
Barnard, A. (2000). History and Theory in Anthropology. Cambridge: Cambridge University Press.

Barton, K. C., y Levstik, L. S. (2004). Teaching History for the Common Good. New Jersey: Lawrence Erlbaum Associates.

Bauman, Z. (201 1). Daños colaterales. Desigualdades sociales en la era global. México: FCE.

Benejam, P. (2004). La selección y la secuenciación de los contenidos sociales. En P. Benejam, P. y J. Pagès (coord.), Enseñar y aprender Ciencias Sociales, Geografía e Historia en la Educación Secundaria (pp.71-96). Barcelona: Horsori

Burke, P. (1996). La Nueva Historia. En P. Burke (ed.), Formas de hacer Historia (pp. 11 -37). Madrid: Alianza Editorial.

Butler, J. (2001). Mecanismos psíquicos del poder: teorías sobre la sujeción. Madrid: Ediciones Cátedra.

Carlson, K. T. (2010). The power of place, the problem of time: Aboriginal identity and historical consciousness in the cauldron of colonialism. Canada: University of Toronto Press.

Chevallard, Y. (1991). La transposición didáctica: del saber sabio al saber enseñado. Argentina: Aique Grupo Editor S.A.

Clark, C. (2014). Sonámbulos. Cómo Europa fue a la guerra en 1914. Barcelona: Galaxia Gutenberg.

Collins, R. (1981). On the microfundations of macrosociology. American Journal of Sociology, 86(5), 984-1014

Dawson, I. (2004). Time for chronology? Ideas for developing chronological understanding. Teaching History, 117, 14-24.

De la Montaña, J. L. (2015). Didáctica de la Historia, historiografía y visibilización de temas, grupos sociales y personas en la enseñanza-aprendizaje de la Historia. En A. M. Hernández Carretero, C. R. García Ruiz y J. L. de la Montaña (coords.), Una enseñanza de las ciencias sociales para el futuro: recursos para trabajar la invisibilidad de personas, lugares y temáticas. AUPDCS y Universidad de Extremadura.

De Oliveira, M. G. (2018). Os sons do silencio: interpelacoes feministas decoloniais a historia da historiografia. Historia da Historiografia, 28(11), 104-140.

Den Heyer, K. (2003). Between every now and then: a role for the study of historical agency in history and citizenship education. Theory and Research in Social Studies Education, $31(1), 411-434$.

Den Heyer, K. (2018). Historical Agency: stories of choice, action and social change. En S. A. Metzer y L. McArthur Harris (eds.). The Wiley International Handbook of History Teaching and Learning (pp. 227-252). Medfore: Wiley Blackwell.

Diamond, J. (2005). Collapse. How some societies choose to fail or succeed. New York: Ciking Express.

Diamond, J. (2012). The world until yesterday. What we can learn from traditional societies. New York: Viking Press. 
Díez Bedmar, M. C. y Fernández Valencia, A. (2019). Enseñanza de las Ciencias Sociales con perspectiva de género. Clio. History and History Teaching, 45, 1-10.

Endacott, J. y Brooks, S. (2018). Historical empathy: perspectives and responding to the past. En S. A. Metzer y L. McArthur Harris (eds.), The Wiley International Handbook of History Teaching and Learning (pp. 203-226). Medfore: Wiley Blackwell.

Fillafer, F. (2017). A World Connecting? From the Unity of History to Global History. History and Theory 56(1), 3-37

Fontal, O. e lbáñez, A. (2015). Estrategias e instrumentos para la educación patrimonial en España. Educatio Siglo XXI, 33(1), 15-32. doi: 10.6018/i/222481

Fontana, J. (1997). Introducció a l'estudi de la història. Barcelona: Crítica

Fontana, J. (201 1). Por el bien del imperio. Una historia del mundo desde 1945. Barcelona: Pasado\&Presente.

Fontana, J. (2013). La historia de los hombres: el siglo XX. Barcelona: Editorial Planeta.

Fontana, J. (2018). L'ofici d'historiador. Barcelona: Arcàdia.

Foucault, M. (2008). Historia de la sexualidad 1: la voluntad del saber. Buenos Aires: Siglo $\mathrm{XXI}$.

Garcés, M. (2019). Nova il/lustració radical. Barcelona: Editorial Anagrama.

García Herreo, M. C. (2005). Del nacer y del vivir. Fragmentos para una historia de la vida en la Baja Edad Media. Zaragoza: Institución Fernando el Católico. Recuperado de https://ifc.dpz.es/recursos/publicaciones/25/10/ ebook.pdf

Giroux, H. (1990). Los profesores como intelectuales. Hacia una pedagogía crítica del aprendizaje. Barcelona: Paidós

Gómez-Carrasco, C. J., López-Facal, R. y Rodríguez-Medina, J. (2019). La investigación en Didáctica de las Ciencias Sociales en revistas españolas de Ciencias de la Educación. Un análisis bibliométrico (2007- 2017). Didáctica de las ciencias experimentales y sociales, 37, 67-88.

González-Valencia, G., Massip, M. y Castellví, J. (2020). Heritage Education and Global Citizenship. En E. M. Delgado-Algarra y J. M. Cuenca-López (eds.), Handbook of Research on Citizenship and Heritage Education (pp. 80-102). IGI Global.

Greer, G. (1985). Sexo y destino. Barcelona: Plaza y Janés.

Gruzinski, S. (2011). Las cuatro partes del mundo: historia de una mundalización. México: Fondo de Cultura Económico.

Guimerá Ravina, C. (1991). Práctica docente y pensamiento del profesor de Historia de Secundaria (Tesis Doctoral). Lleida: Universitat de Lleida.

Guldi, J. y Armitage, D. (2016). Manifiesto por la historia. Madrid: Alianza Editorial

Hernández, E. (2004). Tendencias historiográficas actuales. Escribir historia hoy. Madrid: Akal. 
Henríquez, R. y Pagès, J. (2004). La investigación en didáctica de la historia. Educación XXI. Facultad de Educación. Universidad nacional a distancia, 7, 63-83.

lggers, G. (1998). La ciencia histórica en el siglo XX. Las tendencias actuales: una visión panorámica y crítica del debate internacional. Barcelona: Idea Books.

Jara, M. A. y Santisteban, A. (2018). Los retos de futuro en la enseñanza de las ciencias sociales, la historia y la geografía. En M. A. Jara y A. Santisteban (coords.), Contribuciones de Joan Pagès al desarrollo de la didáctica de les ciencias sociales, la historia y la geografía en Iberoamérica. Universidad Nacional del Comanche y Universitat Autònoma de Barcelona.

Kitson, A., Steward, S. y Husbands, C. (2015). Didáctica de la Historia en Secundaria Obligatoria y Bachillerato. Madrid: Morata.

Kanu, Y. (2005). Teacher's perceptions of the integration of aboriginal culture into the High School curriculum. The Alberta Journal of Educational Research, 51(1), 50-68.

Latouche, S. (2015). Pedagogía del Desastre. En G. D'Alisa, F. Demaria, y G. Kallis (eds.), Decrecimiento. Vocabulario para una nueva era (pp.141-143). Barcelona: Icaria.

Lautier, N. (2006). Introduction. Appropriation des savoirs des sciences humaines et sociales en situation scolaire. En V. Haas (dir.), Les savoirs du quotidien. Transmissions, appropriations, représentations (pp. 71-75). Rennes: Presses Universitaires de Rennes.

Lautier, N. y Allieu-Mary, N. (2008). La didactique de l'histoire. Revue française de pédagogie, 162, 95-131.

Legardez, A. y Simonneaux, L. (2006). L'écol à l'épreuve de l'actualité.Enseigner les questions vives. Issy les Moulineaux: Édition ESF.

Lévesque, S. y Clark, P. Historical Thinking: definitions and educational applications. En S. A. Metzer y L. McArthur Harris (eds.), The Wiley International Handbook of History Teaching and Learning (pp. 119-148). Medfore: Wiley Blackwell.

Levi, G. (1996). Sobre microhistoria. En P. Burke (ed.), Formas de hacer Historia (pp. 119 143). Madrid: Alianza Editorial.

Levy, S. A. (2016). How students navigate the construction of heritage narratives. Theory \& Research in Social Education, 45(2), 157-188.

Lewison, M., Flint, A. y Van Sluys, K. (2002). Taking on critical literacy: the journey of newcomers and novices. Language Arts, 79, 382-292.

López Rodríguez, C. (2015). Repensando las narrativas nacionales: un análisis del origen, transmisión e influencia en el aprendizaje histórico. Panta Rei. Revista Digital de Ciencia y Didáctica de la Historia, 77-92.

Maldonado-Torres, N. (2007). On the Coloniality of Being: contributions to the development of a concept. Cultural Studies, 21 (2-3). 240-270.

Marina, J. A. y Rambaud, J. (2018). Biografía de la humanidad: historia de la evolución de las culturas. Barcelona: Ariel. 
Marolla, J. (2016). La inclusió de les dones en l'ensenyament de la història i les ciències socials. Estudi col/lectiu de casos en les aules xilenes sobre les seves possibilitats i limitacions. Tesis doctoral. Bellaterra: Universitat Autònoma de Barcelona.

Marolla, J. (2017). El profesorado chileno frente a la enseñanza del papel de las mujeres en la historia. Desafíos y ventajas de la transformación de las prácticas. Enseñanza de las Ciencias Sociales, 16, 81-90.

Massip, M. (en prensa). Les ciències socials de rostre humà. Humanitzar els continguts històrics de les ciències socials escolars. Tesis doctoral en curso. Universitat Autònoma de Barcelona.

Massip, M. y Castellví, J. (2019). Poder y diversidad. Los aportes de la Interseccionalidad a la didáctica de las ciencias sociales. Clío. History and History teaching, 45, 139 154.

Massip, M. y Pagès, J. (2016). Humanos frente a humanos. La necesidad de humanizar la historia escolar. En C. R. García, A. Arroyo y B. Andreu, B. (eds.), Deconstruir la alteridad desde la didáctica de las ciencias sociales: educar para la ciudadanía global (pp. 447-457). Las Palmas de Gran Canaria: Universidad de Las Palmas/AUPDCS.

Matozzi, I. (2015). La historia desde abajo en la historia general escolar. En A. M. Hernández Carretero, C. R. García Ruiz y J. L. de la Montaña (coords.), Una enseñanza de las ciencias sociales para el futuro: recursos para trabajar la invisibilidad de personas, lugares y temáticas: AUPDCS y Universidad de Extremadura.

Meneses, B., González-Monfort, N. y Santisteban, A. (2020). La experiencia histórica del alumnado y la historia oral en la enseñanza. Historia y Memoria, 20, 309-343.

Moscovicci, S. (1996). Psicología de las minorías activas. Madrid: Ediciones Morata.

Harari, Y. N. (2014). Sàpiens. Una breu història de la humanitat. Barcelona: Edicions 62.

Pagès, J. (2002). Aprender a enseñar historia y ciencias sociales: el currículo y la didáctica de las ciencias sociales. Pensamiento educativo, 30, 255-269.

Pagès, J. (2015). Saberes Históricos Construidos-Saberes Históricos Apropiados. Una reflexión desde la didáctica de la historia. En E. Zambon, M. Galcerani y C. Paicevich (eds.), Memória, sensibilidades e saberes (pp. 304-326). Campinas, Brasil: Alinea Editora.

Pagès, J. (2018). Las relaciones entre la historia y la historia escolar. Trayectorias Universitarias, 4(7), 31-37.

Pagès, J. (2019). Lliçó magistral, Joan Pagès i Blanch: Els reptes de l'ensenyament de les ciències socials, la geografia i la història. Quin professorat, quina ciutadania, quin futur? En M. Ballbé, N. González-Monfort y A. Santisteban (eds.), Quin professorat? Quina ciutadania? Quin futur? Els reptes de l'ensenyament de les ciències socials, la geografia i la història. (pp.11-36). Bellaterra: GREDICS i Universitat Autònoma de Barcelona.

Pagès, J. y Santisteban, A. (1994). Elements per a un ensenyament renovat de les Ciències Socials. Procediments amb fonts primàries $\mathrm{i}$ aprenentatge de la història. Dins $I$ Jornades de Didàctica de les Ciències Naturals i Socials al Baix Llobregat (pp. 109165) Barcelona, Publicacions de l'Abadia de Montserrat. 
Pagès, J. y Santisteban, A. (2014). ¿¿Qué sabemos sobre la enseñanza y el aprendizaje de la historia en españa? 20 años de investigación. En S. Plá y J. Pagès (eds.), La investigación en la enseñanza de la historia en América latina (pp. 155-192). Universidad Pedaógica Nacional, México: Bonilla Artigas editores.

Plá, S. y Pagès, J. (2014). Una mirada regional a la investigación en la enseñanza de la historia en América Latina. En S. Plá y J. Pagès (coord.), La investigación en la enseñanza de la historia en América Latina (pp.13-38). México DF. Universidad Pedagógica Nacional/Bonilla Artigas Editores.

Porter, R. (1996). Historia del cuerpo. En P. Burke (ed.), Formas de hacer Historia (pp. 5988). Madrid: Alianza Editorial.

Prieto, A. M. (1976). La historia como arma de la reacción. Madrid: Akal.

Real decreto 1006/1991, de 14 de junio, por el que se establecen las enseñanzas mínimas correspondientes a la educación primaria.

Real Decreto 1007/1991, de 14 de junio, por el que se establecen las enseñanzas mínimas correspondientes a la Educación Secundaria Obligatoria.

Real Decreto 1513/2006, de 7 de diciembre, por el que se establecen las enseñanzas mínimas de la Educación primaria.

Real Decreto 1631/2006, de 29 de diciembre, por el que se establecen las enseñanzas mínimas correspondientes a la Educación Secundaria Obligatoria.

Real Decreto 126/2014, de 28 de febrero, por el que se establece el currículo básico de la Educación Primaria.

Real Decreto 1105/2014, de 26 de diciembre, por el que se establece el currículo básico de la Educación Secundaria Obligatoria y del Bachillerato.

Ricoeur, P. (1995). Tiempo y narración: Configuración del tiempo en el relato histórico. Madrid: Siglo XXI

Rina, C. y de la Montana, J. L. (2019). Contingencia e identidad: retos para un diálogo transdisciplinar entre la historiografía y la didáctica de la historia. Tempo e Argumento, Florianópolis, 26(11), 287-317.

Rivera Garretas, M. M. (2010). El cuerpo femenino: genealogías de libertad. En J. Martí y Y. Aixelà (coords.), Desvelando el cuerpo. Perspectivas desde las ciencias sociales y humanas. (pp. 301-316). Barcelona: CSIC. Recuperado de: http://www.mariamilagrosrivera.com/wpcontent/uploads/2017/11/genealogi $\%$ CC $\% 81$ as de libertad.pdf

Rivera Garretas, M. M. (2017). La reina Juana I de España, mal llamada la Loca. Barcelona: Sabina Editorial.

Rüsen, J. (2004). How to Overcome Ethnocentrism: Approaches to a Culture of Recognition by History in the Twenty-First Century. History and Theory, 43(4), 1 18-1 29.

Rüsen, J. (2005). History: Narration, interpretation, orientation. New York, NY: Berghahn. 
Savenije, G. (2011). Discussion in chains. Pupils' ideas about slavery heritage. En C. Van Boxtel, S. Klein y E. Snoep (eds.), Heritage Education: Challenges in Dealing with the Past. Amsterdam: Netherlands Institute for Heritage.

Sabzalian, L. (2019). The tensions between Indigenous sovereingnty and multicultural citizenship education: Toward an anticolonial approach to civic education. Theory and Research in Social Education, 47(3), 311 -346.

Sant, E., Davies, I., Pashby, K. y Shultz, L. (2018). Global Citizenship Education. A critical introduction to key concepts and debates. Chennai: Bloomsbury.

Santisteban, A. y Pagès, J. (2016). La historia y la enseñanza de la historia. Un punto de vista desde la didáctica de la historia y de las ciencias sociales. En M. Jara y G. Funes (comp.), Didáctica de las Ciencias Sociales en la formación del profesorado. Perspectivas $y$ enfoques actuales (pp. 63-85). Universidad Nacional del Comahue.

Santos, B. S. (2019). El fin del imperio cognitivo. La afirmación de las epistemologías del sur. Madrid: Trotta.

Savanije, G., van Boxtel, C. y Grever, M. (2014). Learning about Sensitive History: Heritage of Slavery as a Resource. Theory \& Research in Social Education, 42(4), 516-547.

Scott, J. (1996). Historia de las mujeres. En P. Burke (ed.). Formas de hacer Historia (pp. 255286). Madrid: Alianza Editorial.

Seixas, P. (1993). Historical understanding among adolescents in a multicultural setting. Curriculum Inquiry, 23(3), 301-327.

Seixas, P. (2012). Historical agency asa problem for researchers in history education. Antítesis, 5(10), 537-53.

Seixas, P. (2017). Historical consciousness and historical thinking. En M. Carretero, S. Berger, y M. Grever (eds.), Palgrave handbook of research in historical cultura and education (pp. 59-72). London, England: Palgrave Macmillan.

Sharpe, J. (1996). Historia desde abajo. En P. Burke (ed.), Formas de hacer Historia (pp. 3858). Madrid: Alianza Editorial.

Solsona Pairó, N. (2019). El coneixement androcèntric i la construcció d'un nou saber. Dossier Graó: Coeducar, posar la vida al centre, 20-24.

Suny, R. G. (2002). Back and Beyond: Reversing the Cultural Turn? The American Historical Review, 107, 1476-1499.

Tutiaux-Guillon, N. (coord.) (2018). Enseigner l'histoire en contexte de pluralité identitaire. La revue française d'éducation comparée, 17. L'Harmattan.

Villalón, G. y Pagès, J. (2013). ¿Quién protagoniza y cómo la historia escolar? La enseñanza de la historia de los otros y de las otras en los textos de estudio de Historia de Chile de educación primaria. Clío\&Asociados, 17, 119-136.

Vuillard, E. (2019). 14 de julio. Barcelona: Tusquets Editores.

Walton, S. (2005). Humanidad. Una historia de las emociones. Madrid: Taurus.

Wiesner-Hanks, M. (2008). Do women need the Renaissance? Gender and History, 20, 539557. 
Yuste Munté, M. y Mondèjar Torra, E. (2017). ¿Para qué sirve estudiar ciencias sociales? Reflexiones de un grupo de alumnado gitano sobre el aprendizaje de la geografía y la historia. En R. Martínez Medina, R. García-Moris y C. R. García Ruiz (eds.), Investigación en didáctica de las ciencias sociales. Retos, preguntas y líneas de investigación (pp. 823-832). Universidad de Córdoba y AUPDCS.

Zeldin, T. (1997). Historia íntima de la humanidad. Madrid: Alinaza Editorial. 


\section{Panta Rei}

PANTA REl es una revista digital de investigación orientada a la Historia y la Didáctica de la Historia. Su principal objetivo es la transmisión del conocimiento científico, dando una oportunidad también a los jóvenes investigadores que quieren abrirse camino en el estudio de las ciencias humanas y sociales. Se compone de estudios originales relacionados con la disciplina histórica así como su didáctica y difusión. Las diferentes secciones que componen la revista son: artículos de investigación, entrevistas a profesionales, recensiones de monografías de actualidad y crónicas de congresos o eventos científicos relevantes.

Todos los artículos publicados son objeto de un proceso de revisión a cargo de un mínimo de dos evaluadores, que se consideran expertos en el ámbito temático del artículo propuesto. Nuestro deseo es poder ofrecer unos contenidos rigurosos, de calidad y de interés.

El CEPOAT (Centro de Estudios del Próximo Oriente y la Antigüedad Tardía de la Universidad de Murcia) es la institución encargada de la coordinación y gestión de la revista, desde donde anualmente se lanzará la convocatoria para aquellos que estén interesados en publicar sus trabajos, siempre relacionados con la Historia y la Didáctica de la Historia.

PANTA REI is a digital journal focused on History and Teaching History. Its main objective is the transmission of scientific knowledge by giving also an opportunity to young researchers who want to make their way in the study of human and social sciences. It is composed by original studies related to History, as well as its didactics and promotion. The different sections of this journal are: research articles, interviews to professionals, recensions on monographs about current issues and reports about congresses or relevant scientific events.

All the articles published are subject to a revision process carried out by a minimum of two reviewers who are considered to be experts in the field of the article proposed. Our wish is to offer rigorous contents with quality and being of interest to the reader.

CEPOAT (Centre of Studies of the Middle East and Late Antiquity of the University of Murcia) is the institution in charge of the coordination and management of this journal. This is the centre from where the call for papers will be launched annually for all the people interested in publishing their papers, always related to History and Teaching History. 


\section{Normas de publicación}

El autor se compromete a enviar trabajos originales, que no se encuentren publicados en otras revistas ni en otros idiomas. Así mismo, el mismo artículo no podrá ser presentado en otras revistas mientras dure el proceso de evaluación.

\section{Envío y presentación de originales}

Las normas de edición y forma de envío de artículos a la revista se pueden consultar en https://revistas.um.es/pantarei/

Para la redacción de los trabajos se tendrá en cuenta el Manual de la American Psychological Association, en su $7 .^{a}$ edición. La extensión máxima de los trabajos será de 25 páginas. La revista acepta originales escritos en español o inglés.

\section{Proceso de valoración y evaluación}

Una vez recibidos los trabajos, la Revista realizará una primera valoración. Si el trabajo enviado se ajusta a las normas de presentación propuestas, la temática es coincidente con la línea editorial de la revista y posee la calidad científica necesaria, será remitido al consejo asesor para una primera evaluación. Si no es así en este primer paso se puede rechazar directamente los documentos que incumplan claramente la línea editorial.

Será el Consejo Asesor quien indique a la revista la originalidad, relevancia, estructura, redacción, aparato bibliográfico, etc. del trabajo enviado y, para ello, se designará a dos revisores expertos externos que evaluarán cada uno de los trabajos, que pueden formar parte (o no) de este Consejo Asesor. La selección de los revisores se ajustará a la temática y características metodológicas del trabajo. El nombre y filiación de los autores serán eliminados del trabajo para su revisión, así como los revisores actuarán de manera anónima y confidencial.

Los revisores deberán rellenar un informe de evaluación que centrará su atención en aspectos tales como características formales, originalidad y novedad de los trabajos, relevancia de las propuestas y los resultados, calidad metodológica y validez científica.

Una vez terminado el proceso se decidirá la aceptación o no de los mismos y su publicación en el número que sea pertinente, así como las modificaciones susceptibles de ser realizadas para su final publicación. Dicha notificación se enviará únicamente por correo electrónico, en un plazo máximo de seis meses. 


\section{Publishing rules}

The author is committed to submit original papers not having been published in other reviews or in other languages. In this way, it is not allowed for the same paper to be presented in other reviews during the evaluation process.

\section{Submission and presentation of originals}

The editing rules and the guidelines for the submission of papers can be consulted at https://revistas.um.es/pantarei/

The seventh edition of the Manual of the American Psychological Association will be taken into account for the writing of the papers. The length of the submitted papers will not exceed the 25 pages. The journal accepts originals written in Spanish or English.

\section{Examination and assessment process}

The Journal will submit the papers to a first examination once received. If the paper follows the presentation guidelines, the subject agrees with the editorial line of this journal, and possess the scientific quality required, it will be sent to the advisory council for a first assessment. If not, the documents which clearly fail to complete the editorial line may be rejected straightaway in this first step.

The Advisory Council will indicate the originality, relevance, structure, writing, bibliography, etc. of the text to the journal; for this purpose, two outside experts will be designated to review the papers; these experts can be (or not) part of this Advisory Council. The selection of the experts will adjust to the subject and methodological characteristics of the paper. Name and affiliation of the author will be eliminated from the text for its review, in this way experts will act anonymously and confidentially.

The experts will fill out an assessment report which will focus on aspects such as formal characteristics, originality and novelty of the papers, relevance and results of the proposal, methodological quality and scientific validity.

Once the process is finished, the acceptance or not of the papers and its publication in the corresponding edition will be decided, as well as the modifications that may be done for its final publication. This notification will be sent by email within 6 months maximum. 


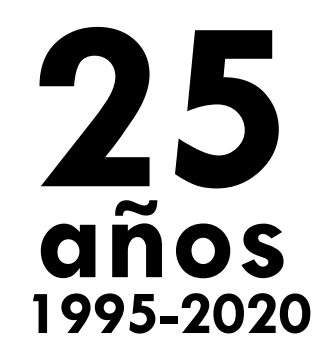

\section{cepoAt editum}

